\title{
Effective Expressions of Agency in a Broad Network of Relationships
}

\author{
by
}

\author{
Emily Jacobs
}

A thesis submitted to the Faculty of Graduate and Postdoctoral Affairs in partial fulfillment of the requirements for the degree of

Master of Arts

in

Philosophy

Carleton University

Ottawa, Ontario

(C) 2016, Emily Jacobs 


\begin{abstract}
I argue that while Amartya Sen provides good reasons for focusing on the agency aspect of individuals, his account is too constrained. Sen describes agency in terms of individuals and their capacity for rationality and fails to account for the effect of a broad network of relationships. I turn to Sarah Clark Miller's expanded account of agency to argue that the abilities of relationality and emotionality are also relevant for effective agency. I then argue that Miller's focus on the moral duty to care means that her account is also too individualistic. I ground her account instead in the thoroughly relational nature of agents to show that her account must be coupled with a relational account of autonomy to be adequately sensitive to the effects of oppression on agents. I end by suggesting that oppressed agents can challenge social conditions that are not completely conducive to full autonomy through solidarity.
\end{abstract}




\section{Acknowledgements}

There were many people who made this thesis possible. First and foremost, I must thank my supervisor Christine Koggel. I could not have made this project what it was without her continuous support in the development of my ideas, arguments, and writing. She introduced me to these concepts in the first place and has been present at every step as my understanding continued to grow and progress. This thesis literally could not have been without her.

I would also like to thank Jay Drydyk, Alexis Shotwell, and Dave Matheson for their participation in my defense. Jay expressed interest in my project at its infancy and Alexis Shotwell's work was invaluable to the development of solutions within my thesis. It is incredibly exciting to have people who were important to the crafting of this thesis to sit on the defense committee and help me to make the project even better. And of course, I must give a special mention to Sandy Kirkpatrick, office administrator extraordinaire, who somehow can answer any question you have and offer help no matter the need. Having a chat with her on the way into the office always put me in the right mood to have a productive day.

I could not have enjoyed my time while writing if it were not for many supportive friends and colleagues. I was lucky to have Jonathan Reardon, Aaron Nowaczek, Michael Tremblay and Patricia Pajunen as members of my cohort who especially challenged and supported me throughout the many steps of development of my thesis ideas. In particular, Patricia was always around to listen to my rants and ravings on oppression and offer her solidarity in my continuous thesis writing struggles. I also have to thank the some students who came before me, Timmy Grainger and Drew Hoult, who took the time to sit 
through a tutorial on Feminist Ethics while trying to write their own theses. It would have been a much more difficult learning experience without you two along for the ride.

The cohort ahead of me also had a hand in keeping me sane and grounded throughout this process. Thank you to Holly Longair, Arielle Stirling, Sebastian Rodriguez Duque, and Jo Chalupiak for being around the office for support. There was always someone around available to chat and oftentimes I really needed that. I appreciated your presence. I must say that Amy Keating and Courtney Lindsay were especially important to my happiness, sanity, and general health throughout this absurd time. I value your friendships deeply. Courtney was always available to hang out and Amy was always around to laugh at my jokes. Both helped a lot in keeping me from losing my head completely.

On the rare occasions that I was not chained to my desk, many of those listed above made my life outside of writing amazing. Amy and Courtney both graciously opened their homes to me when I needed a place to stay that was closer to campus. I also had friends in other places to help me along the way. Regina Taptich has been my friend from the start of my philosophical journey and has continued to help me out (through some intense phone call sessions) despite her desertion of Ottawa (McMaster is alright too I guess). I don't know if Regina realizes how important she was to me through the years. If it wasn't for her, I wouldn't have developed the confidence I needed to have in both my ideas and myself. All the time we spent together helped me so much to become the person I am today. She was an integral part of my life both within and outside academics. Cynthia Charlton has also been important to me, offering her words of encouragement and support from Montreal at all hours of the day and night. I needed her 
to do the work to maintain our friendship because I often had little time to think of things outside of this project. Thank you Cynthia for always reaching out and listening to me. You always made time to hear me out not matter what I was on about and for that I am grateful. Lastly, while Drew Hoult definitely helped out around the office, he was also a noteworthy friend. Thank you Drew for offering support when you were able. It was incredibly valuable and most definitely appreciated. Sometimes you seemed to understand my struggles in a way many could not. You made it easy to be most honest with what I was really feeling even when I had a hard time sharing that with others. It was a comfort to know that if ever I needed someone you would be there. Thank you to everyone who was there when I really needed them to be.

This could not have been completed without the support of my roommates who became much like a family. Thank you to Becca McDonald, Thomas Leckey, and especially Samantha McDonald. It would have been incredibly hard to write this thing without a happy and loving home life. Sam, you not only made my house a home, but were also a kind, helpful, and encouraging friend throughout my life. I know you tried really hard to do what you could to help me and I am incredibly thankful for that.

I was lucky to have so many people who were ready to listen to me and offer whatever I needed if they could. It felt as if you were all my family; or at least became a part of my family. I needed you all because my actual family is a little small. Just a little unit of four; but a great unit at that. I am grateful to have parents who were supportive of my goals no matter what they were. I'm sure many a parent has balked at the study of 'philosophy' but I heard no such judgment. I think that no matter what I chose to do they would be behind me; they're just those sort of people. It was also very helpful to have 
parents (well really, I'm looking at you mom) who worked hard to be financially supportive so I didn't have to worry so much about those things. To Mom: I could not be the independent, intelligent, thesis-writing person I am today without your constant love and support throughout my life. At the end of the day, when it seemed like no one else could totally understand what it is I needed, I went to you. You may not always feel appreciated but please know that you are. When it seems like I don't need you it's only because you did such a good job in the first place. To Dad: I know a lot of who I am comes from you even if sometimes I don't want to believe it. I think it's a lot of the good parts of me too. I know you were there for me in the ways you knew how to be. (And thankfully mom was around for when that wasn't enough!) To Evan: It was always great for my confidence to have someone looking up to me (even if you would never admit it!) I like to think I helped a little bit in you becoming the person you are. I am so proud of you and think so much of our individual success comes from each other. I needed a little brother and I like to think you needed me too. You three have played a crucial role in helping me become the person I am today. I love you. Thank you. 


\section{Table of Contents}

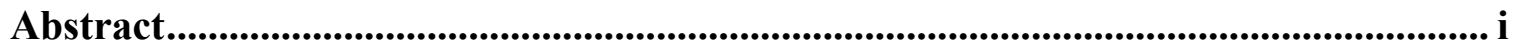

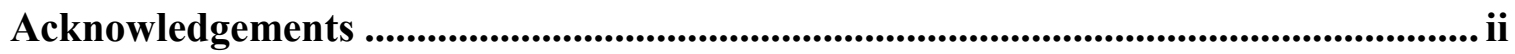

Introduction ................................................................................................................ 1

Chapter 1: Sen's Conception of Agency ................................................................................... 7

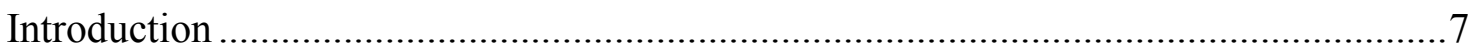

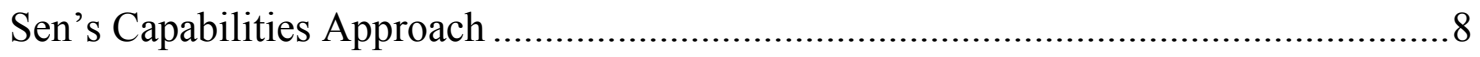

The Distinction between Well-being and Agency ...................................................10

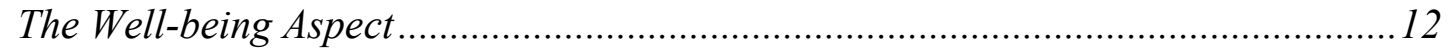

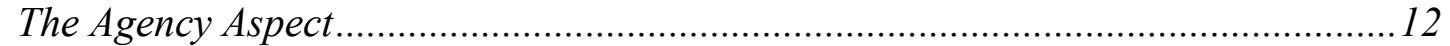

The Capabilities Approach in Summary.............................................................. 13

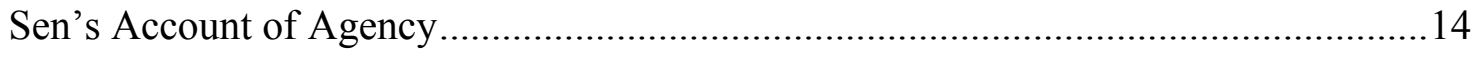

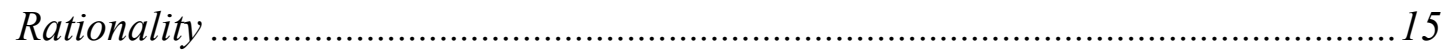

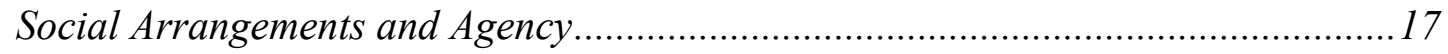

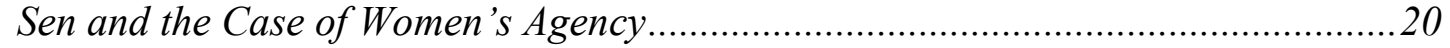

The Problems with Sen's Conception of ‘Agency' .................................................23

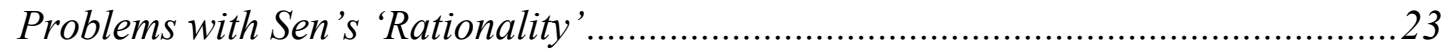

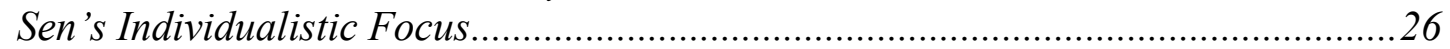

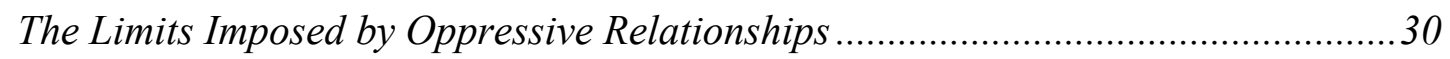

Conclusion: The Need for Recognition of Relationality............................................35

Chapter 2: An Expanded Account of Agency ........................................................ 36

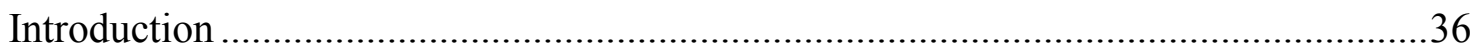

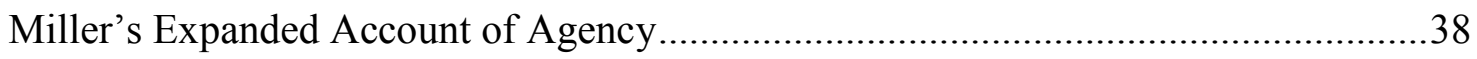

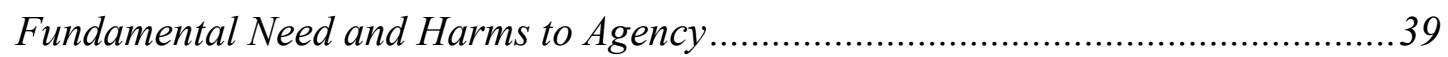

The Provision of Care ......................................................................................... 40

Relationality, Emotionality, and Rationality in Connection with Agency..................42

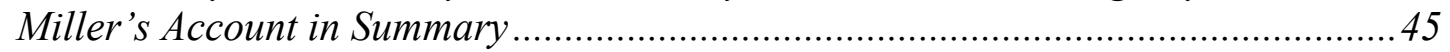

The Problems with Miller's Account of Agency: Not Relational Enough ...................46

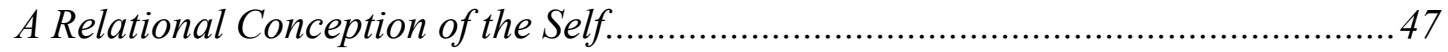

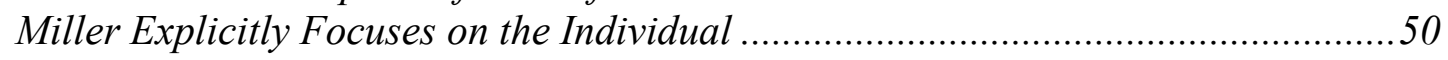

Expanding Miller's Account of Agency: The Fact of Relationality .............................52 


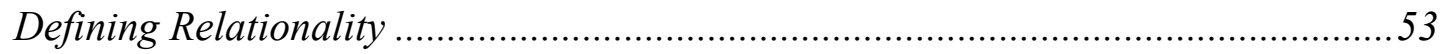

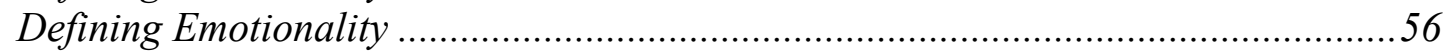

The Inextricable Interconnection of Relationality, Emotionality, and Rationality ....58

The Complexity of Expressing Agency: The Divided Interests of Agents...................61

Conclusion: The Need for an Account of the Broad Network of Relationships.............64

Chapter 3: Oppression and Autonomy: Supplementing an Account of Agency ...... 66

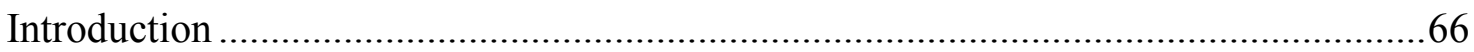

The Distinction between Agency and Autonomy ……...........................................67

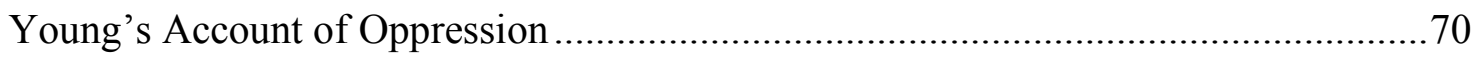

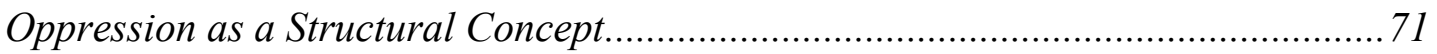

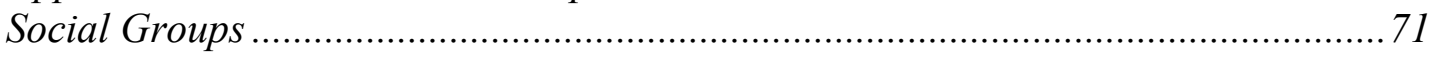

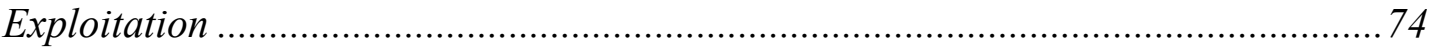

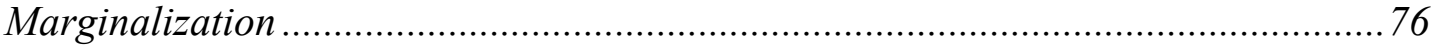

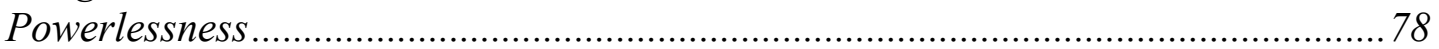

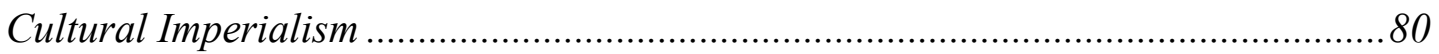

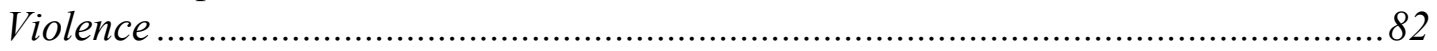

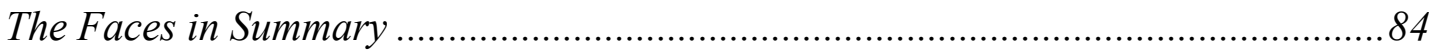

Revisiting Problems with Sen and Miller: Oppression and Agency ..............................85

A Relational Account of Autonomy.........................................................................91

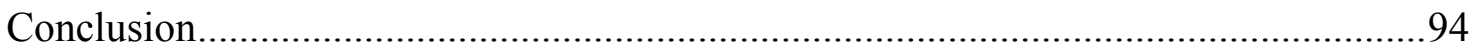

Chapter 4: Changing Conditions: Resistance in the Face of Oppression.................... 96

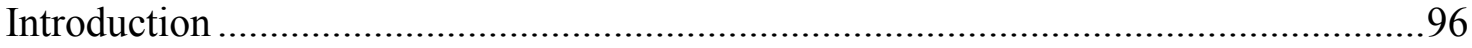

Meyers's Account of Autonomy ………………........................................................97

The Three Competencies: Self-discovery, Self-definition, and Self-direction............98

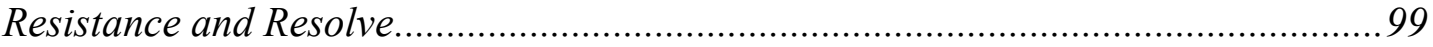

Problems with Meyers's Account of Autonomy ..........................................................100

What Can Be Done?: Solidarity and Collective Action ....................................................103

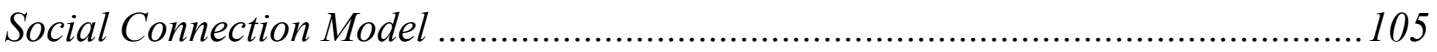

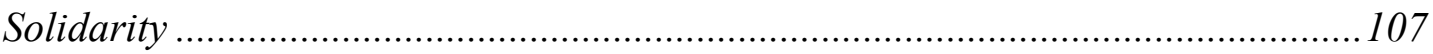

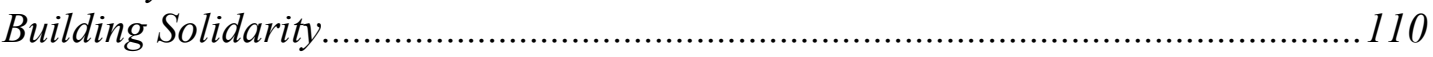

Concluding Remarks: Effective Expressions of Agency and Relationality .................113

Bibliography .............................................................................................................................. 116 


\section{Introduction}

This project was motivated by my interest in combining insights from literature in development ethics with that from feminist theory. In development ethics literature, there is the tendency for theorists to focus on 'agency'. ${ }^{1}$ Meanwhile, a lot of feminist literature tends to be more focused on 'autonomy'. ${ }^{2}$ Both realms of literature have a variety of important insights when considering how to help people live better lives and expand their freedom to control their own lives in a world that explicitly and implicitly limits some from doing so. While development ethics is often focused on individuals and their ability to express agency, feminist theory is more concerned with the broader social conditions that are conducive to autonomy.

On the development ethics side, Amartya Sen argues that people are concerned with both their own well-being and their available freedom: that is, people want to be recognized as and able to effectively act as agents. ${ }^{3} \mathrm{He}$ argues that effective human development requires recognition of the agency aspect of individuals and moves away from treating people in developing countries as patients of Western development projects. ${ }^{4}$ This is because Sen argues that "with adequate social opportunities, individuals can effectively shape their own destiny and help each other. They need not be seen primarily as passive recipients of the benefits of cunning development programs. ${ }^{\circ 5}$ No matter the state of one's well-being, their particular perspectives, goals, life plans, and

\footnotetext{
${ }^{1}$ See Amartya Sen, David Crocker, Ingrid Robeyns, Naila Kabeer, Christine Koggel, Ann E. Cudd, and Marianne T. Hill.

${ }^{2}$ See Susan Sherwin, Catriona Mackenzie, Natalie Stoljar, Jennifer Nedelsky, and Diana T. Meyers.

3 Amartya Sen, Development as Freedom (Oxford: Oxford University Press, 1999), 18-19.

${ }^{4}$ Sen, Development as Freedom, xi-xii, 3-4, and ibid.

${ }^{5}$ Sen, Development as Freedom, 11.
} 
values are not to be dismissed; free agency matters even for those who are experiencing a relatively lower quality of life. ${ }^{6}$

However, a major problem with an agency-centered approach is it tends to be too individualistic. Catriona Mackenzie and Natalie Stoljar claim that feminist critiques "point to the need to think of autonomy as a characteristic of agents who are emotional, embodied, desiring, creative, and feeling, as well as rational creatures." ${ }^{.7}$ It is these characteristics that individualistic accounts such as Sen's strip away from the agent despite the fact that they are fundamental to her very being. Background structures and conditions have an overwhelming impact on the possibilities for the expression of agency for particular agents. Drawing on insights from various feminist theorists, I will argue that for an account to accurately encapsulate 'agency' it must be sensitive to the fundamentally relational nature of agents. The inadequacy of Sen's account in part comes out of his failure to do so.

Serene J. Khader claims that "feminists who theorize about oppression and deprivation are faced with a balancing act— that of trying to represent deprived people as agents without thereby obscuring the reality of their deprivation." ${ }^{\prime 8}$ There is a concern throughout feminist literature for treating women facing oppression as agents without dismissing the harmful effects of that oppression. Many feminist theorists tend to handle this problem by assuming people are agents and theorizing instead about whether or not they are 'autonomous' agents. In other words, feminist theorists bracket the discussion of 'agency' and focus instead on 'autonomy' in an attempt to avoid treating oppressed

\footnotetext{
${ }^{6}$ Sen, Development as Freedom, 14-25.

${ }^{7}$ Catriona Mackenzie and Natalie Stoljar, eds. Relational Autonomy: Feminist Perspectives on Autonomy, Agency, and the Social Self (New York: Oxford University Press, 2000), 21.

${ }^{8}$ Serene J. Khader, Adaptive Preferences and Women's Empowerment (New York: Oxford University Press, 2011), 30.
} 
women as a homogenous group of individuals incapable of making choices for their own good. Mackenzie and Stoljar argue that "the notion of autonomy is vital to feminist attempts to understand oppression, subjection, and agency." In Diana T. Meyers's book, she discusses "personally autonomous agents" and goes into extensive detail concerning what 'autonomy' consists in without much mention of the content of 'agency'. ${ }^{10}$ Feminist theorists note that autonomy tends to be absent in the face of oppression. For instance, Susan Sherwin states that an oppressed agent will be subject to the "phenomena of actively supporting activities that reinforce one's own oppression ... no matter which option one chooses. There are negative consequences for the agent. ... a person can certainly display agency ... but it does not seem right to call her choice autonomous when the structure does not offer her any option that fully reflects her deepest values and interests." ${ }^{.11}$ Khader argues that an agency centered approach cannot fully account for the barriers to women's empowerment and calls for a relational account of autonomy to fully address those factors that stand in the way of one's ability to act as effective agents in the way Sen parses out. ${ }^{12}$

Fundamental to feminist theory is the need to respect the unique perspectives, situatedness, and vulnerability of agents and to instead focus on their ability to be autonomous; leaving it open to particular agents to decide how it is they would like to navigate the world according to whatever choices they deem rational to make. ${ }^{13}$

\footnotetext{
${ }^{9}$ Mackenzie and Stoljar, Relational Autonomy, 3.

${ }^{10}$ Diana T. Meyers, Self, Society, and Personal Choice (New York: Columbia University Press, 1989$), 19$.

11 Susan Sherwin, "Relational Autonomy and Global Threats," in Being Relational: Reflections on Relational Theory and Health Law, ed. Jocelyn Downie and Jennifer J. Llewellyn (Vancouver: UBC Press, 2012), 18-19.

12 Serene J. Khader, "Beyond Autonomy Fetishism: Affiliation with Autonomy in Women's Empowerment," Journal of Human Development and Capabilities 17.1 (2016): 125-139.

13 Sherwin, "Relational Autonomy and Global Threats," 18-19.
} 
Throughout this thesis, I work to meld the contributions from these two domains as each can provide insights that the other appears to miss. While development ethicists work hard to note the individuated criteria for effective expressions of agency, feminist theory is more focused on broad social conditions and the ways in which overarching structures of relationships condition particular agents. Since feminist theorists treat autonomy as secondary to agency, I will argue that an account of agency remains important for ensuring people are autonomous. I draw on Sen's account of agency due to his particular sensitivity to the differing values and choices of agents situated differently within the world. However, Sen's account falls into many traps that feminist theorists specifically attempt to avoid. It is restricted to rational and coherent life plans and is not sufficiently sensitive to the fact of relationality and the effects of oppression on agents. In this thesis, I move back and forth between these two literatures to capture features and shortcomings of each and gesture in the direction of solutions that can better capture what is at stake when we talk about "human development".

Drawing on Sen's capabilities approach in Chapter 1, I argue that agency is important for human development. However, Sen's account of agency falls short on a number of fronts: he focuses too exclusively on rationality, his account is too individualistic, and he does not adequately address the effects of broad networks of relationships on agents' freedom to do and be in ways they have reason to value. In particular, all broad networks of relationships that exist in our world manifest oppression. In this way, some agents will be restricted from expressing their agency for reasons that cannot be combatted through the expansion of the kinds of freedoms that Sen recommends. I also move away from considering 'agency' only in terms of development 
ethics. Effective expressions of agency are important for all people and so an account of agency could be applied to all persons; not only those situated in underdeveloped contexts.

I handle some of my criticisms of Sen in Chapter 1 through the addition of Miller's expanded account of agency in Chapter 2. Miller suggests that relationality and emotionality are also important for effective expressions of agency. She couches her account of agency in a duty to care for the fundamental needs of others due to the harms to agency that agents experiencing fundamental needs face. I argue that Miller's account is still too individualistic. Due to her focus on the moral obligations particular agents owe one another, she also misses the effect that broad networks of relationships have on particular agents. I handle this concern in part by basing her account in a more thoroughgoing relational account of agents in place of an individual-centered duty to care. However, this change is not enough to address all my concerns with accounts of agency that fail to be sensitive to the effects of oppressive social conditions.

In Chapter 3, I argue that accounts of agency will be held up at the point at which there is nothing that can be done by particular agents (or for an agent in particular) to address the limits imposed by oppressive social conditions. I offer Iris Marion Young's account of oppression to demonstrate the many ways oppression can affect particular agents, their expression of agency, and the strength and content of their agential skills of relationality, emotionality, and rationality. This demonstrates the need for a separate account, an account of relational autonomy, to address the effects of oppression on agents. I then draw on the accounts of relational autonomy developed by Susan Sherwin and Catriona Mackenzie to clarify the ways in which oppression will shape social 
conditions and thereby affect what agents are able to do and be. Their accounts demonstrate the need for entire networks of relationships to change in order to dismantle oppressive norms, structures, and relationships.

In the final chapter, Chapter 4, I argue that dismantling oppressive structures will require the collective efforts of agents acting in solidarity with one another. This is because it is too much to ask particular agents to resist oppression on their own. Oppressed agents can experience many risks and harms in the face of oppression when attempting to challenge oppression on their own. I raise objections to Diana T. Meyers's account of how an individual can resist oppression because her account rests on conceiving agents as possessing unified, authentic selves that make it possible for them to know how they can resist relationships with others to maintain autonomy. It is far more complicated than this due to the thoroughly relational account that shows agents to have multiple and conflicting values that still allow them to be effective agents even under conditions of oppression. Agents will be best served by working in and through their relationships so as to work together to challenge oppression. This is both because oppression is caused collectively and because the thoroughly relational nature of agents will make it difficult for them to resist particular relationships when faced with trade-offs. It is possible to change conditions that are not conducive to full autonomy for all agents. However, it will take many agents, acting in solidarity, through the use of relational, emotional, and rational abilities, for such movements to be most effective. 


\section{Chapter 1}

\section{Sen's Conception of Agency}

\section{$\underline{\text { Introduction }}$}

I will begin with an exploration of the basic tenets of Sen's version of the capabilities approach. Sen argues that agency, alongside well-being, is important for effective human development. In this chapter, I will lay out the main concerns this approach identifies when looking to facilitate development. This will demonstrate the emphasis Sen places on agency when it comes to effective human development. I will then focus on Sen's account of agency more specifically. While he argues that agency is important for facilitating development for the worst off, I will be applying his concern for agency more generally as everyone can stand to have their agency expanded. Sen's account of agency is connected to freedom, rationality, and independence. I will clarify these aspects of his account.

I will then argue that Sen's account of agency is not adequately sensitive to the fundamentally relational nature of human beings or the ways in which this fact will affect an individual's ability to act as an agent. In particular, he takes rationality, restrictively defined, to be the only faculty that matters for agency. I argue that rationality is not the only faculty that matters for effective expressions of agency, that rationality is itself constituted relationally, and that an agent's rational development requires that other people necessarily pursue activities that are not purely self-serving. A conception of reason must be founded on our relationships with other people and their concern for us and not only on one's own rational life plan. Otherwise, rationality can never develop in the first place. Sen also conceives of the agent individualistically. This will lead to many 
problems for an account of agency as agents are not the independent, self-focused characters Sen makes them out to be.

In part due to his individualistic account of the agent, Sen also fails to adequately recognize the impact of broader social arrangements of oppression. Together, these issues signal a failing of Sen's account of agency as it currently stands. Therefore, while I agree with Sen that expanding agency is important for the general improvement of human lives, I argue that his account of agency is too narrow. It does not include all the faculties relevant to agency, it does not appreciate the fundamentally relational nature of agents, and it does not recognize the impact of oppression. It is for these reasons that I go on to develop an expanded account of agency in Chapter 2. In Chapter 3 I will argue that an expanded account of agency must be coupled with an account of autonomy to address the impact of oppression on agents. Sen's account must be expanded in order to cover all the factors that are relevant to the effective expression of agency.

\section{$\underline{\text { Sen's Capabilities Approach }}$}

Sen's capabilities approach takes human development "as the process of expanding the real freedoms that people enjoy." ${ }^{14}$ Sen explains that:

Individual advantage is judged in the capability approach by a person's capability to do things he or she has reason to value. A person's advantage in terms of opportunities is judged to be lower than that of another if she has less capability — less real opportunity - to achieve those things that she has reason to value. The focus here is on the freedom that a person actually has to do this or be that - things that he or she may value doing or being....The idea of freedom also respects our being free to determine what we want, what we value and ultimately what we decide to choose. ${ }^{15}$

${ }^{14}$ Sen, Development as Freedom, 3.

${ }^{15}$ Amartya Sen, The Idea of Justice (Cambridge: Harvard University Press, 2009), 231-232. 
The primary focus is on people's capability to be and to do things which they have reason to value. Sen argues that increasing a person's capabilities will coincide with the presence and expansion of their freedom. In order to be able to claim someone has the capability to do something, the opportunity to do so must be present and the individual must really be free to take advantage of that opportunity. People must be free to decide their course of life in terms of what they decide to value. ${ }^{16}$ This approach leaves the design of a person's life up to her and restricts others from prescribing specific ways of being to her. Freedom requires not only having actual access to some opportunities but access to a varied set of possible options. One must be able to choose from a varied set of options to truly be free to choose. Offering a single opportunity is not real freedom because an individual must choose that option or be left with nothing. ${ }^{17}$ In this sort of case, the choice is no real choice at all.

For instance, offering the opportunity for employment in a factory can appear to be a way to expand a person's freedom. An individual has an extra choice in terms of possibilities for employment where that option did not exist before. The income earned at this job could then be used to freely secure other goods that that person values. However, if the only available job is as a factory worker, and the alternative is no career and destitution, the individual is fairly constrained in her available freedom. It is almost as if she is forced to take advantage of the job offer, even if it is not something she wants because the alternative, destitution, is not a real alternative. In this example, the person would need to be offered a variety of job opportunities to be considered truly free to decide for herself. Sen argues that expanding substantive freedoms facilitates

\footnotetext{
${ }^{16}$ Sen, Idea of Justice, 232.

${ }^{17}$ Sen, Development as Freedom, 27.
} 
development as "greater freedom enhances the ability of people to help themselves and also to influence the world." ${ }^{\prime 18}$ Freedom is the tool people can use to realize whatever goals and values they so choose. According to Sen, development should be measured by the freedoms available to people as the absence of freedom directly imposes limits to the feasibly available options available to people to improve their own lives. ${ }^{19}$

\section{The Distinction between Well-being and Agency}

Sen distinguishes two important aspects of freedom: well-being and agency. Sen explains that, “a person's capability can be characterized as well-being freedom (reflecting the freedom to advance one's own well-being), and agency freedom (concerned with the freedom to advance whatever goals and values a person has reason to advance). ${ }^{, 20} \mathrm{He}$ distinguishes well-being from agency because the strict pursuit of well-being in certain specific terms may not always match the broader aims of particular individuals. One must respect people's particular goals, values, and desires to effectively expand their freedom. It would be incorrect to prioritize only well-being because it would not allow people to determine for themselves the way they want their lives to go. People should be free to pursue lives they have reason to value and be free to decide for themselves how such a life should look.

In reference to the difference between well-being and agency, Sen explains that,

While the former may be of more general interest to public policy (such as poverty removal, in the form of eradicating major deprivation in well-being freedom), it is the latter that can, arguably, be seen as being of primary interest to the person's own sense of values. If a person attaches more importance to

\footnotetext{
18 Sen, Development as Freedom, 18.

19 Sen, Development as Freedom, 3-4.

${ }^{20}$ Sen, Idea of Justice, 288-289.
} 
some goal, or some rule of behaviour, than to personal well-being, it is a decision that could be seen to be for him or her to make. ${ }^{21}$

Sen argues that people must be able to choose not to achieve well-being should it conflict with their own personal values or life goals. ${ }^{22}$ We must respect individuals' values and goals, even in the case that they seem at odds with what others may find relevant for well-being. For instance, being well nourished may appear to be something everyone would wish to secure. However, it could be the case that an individual has other values that, when given the freedom to choose, would cause them to choose not to be wellnourished. Perhaps this individual has chosen to fast for a certain period of time due to religious beliefs that they have decided to prioritize over their need for food. ${ }^{23}$ What is important in this situation is agency: the individual must be free to pursue the achievement of well-being in a way that fits with the broader scheme of her beliefs concerning what a good life consists in for her. ${ }^{24}$ According to the capabilities approach, these options ought to be made available because well-being as well as agency are relevant to human development.

It is best to focus on expanding access to capabilities as this leaves the design of one's life up to the individual and thereby respects their agency freedom. Within this distinction, there is the further distinction of achievement and freedom. There are then four concepts that bear on the advantage experienced by an individual: well-being achievement, well-being freedom, agency achievement, and agency freedom. ${ }^{25}$ Freedom is so important in Sen's account because it should be left up to individuals to decide how

\footnotetext{
21 Sen, Idea of Justice, 289.

22 Sen, Idea of Justice, 287.

23 Sen, Development as Freedom, 76.

${ }^{24}$ Sen, Idea of Justice, 289.

25 Sen, Idea of Justice, 287.
} 
it is they will achieve well-being and realize their agency. I will describe components of the well-being aspect in order to further distinguish it from the more important agency aspect. I will then focus on the parts of Sen's account of agency more specifically.

\section{The Well-being Aspect}

Sen claims that "the well-being of a person can be seen in terms of the quality (the 'well-ness', as it were) of the person's being." ${ }^{26}$ The quality can be considered in objective terms, as in which beings and doings objectively confer greater quality of life to the person in question. Sen identifies some possible examples of well-being achievement: "being adequately nourished, being in good health, avoiding escapable morbidity and premature mortality, etc., ... being happy, having self-respect, taking part in the life of the community, and so on. ${ }^{27}$ All of these things contribute to the overall wellness of 'being' an individual can enjoy. The presence of realized well-being signals well-being achievement. Good development is, in part, characterized in terms of securing greater well-being achievement in human lives. Well-being freedom is the freedom to pursue well-being achievements. Development is facilitated through the removal of impediments to the freedom to pursue well-being achievements that individuals decide they wish to pursue.

\section{The Agency Aspect}

According to Sen, "agency encompasses all the goals that a person has reasons to adopt, which can inter alia include goals other than the advancement of his or her own well-

\footnotetext{
${ }^{26}$ Amartya Sen, Inequality Reexamined (New York: Oxford University Press, 1995), 39.

${ }^{27}$ Ibid.
} 
being." ${ }^{28}$ Agency goes beyond well-being as well-being freedom is subsumed by agency.

Sen distinguishes two facets of agency in a similar way as he does with well-being:

agency achievement and agency freedom. Sen explains that agency achievement is "the

realization of goals and values she has reasons to pursue. ${ }^{29}$ Similar to well-being

achievement, agency achievement is characterized by the actual realization of specific

beings and doings. Sen characterizes agency freedom as:

What the person is free to do and achieve in pursuit of whatever goals or values he or she regards as important. A person's agency aspects cannot be understood without taking note of his or her aims, objectives, allegiances, obligations, andin a broad sense- the person's conception of the good. ... Agency freedom is freedom to achieve whatever the person, as a responsible agent, decides he or she should achieve. ${ }^{30}$

Agency freedom is concerned with the freedom to determine one's own values and goals, as selected from a variety of alternate life plans, so as to determine what one prefers. ${ }^{31}$ This freedom underwrites agency achievement because people must be free to determine for themselves what it is they value as well as being free to pursue those values. Agency achievement depends on the freedom to choose one's goals in the first place.

\section{The Capabilities Approach in Summary}

Sen argues that human development is made possible through the expansion of wellbeing and agency freedom. These together form the content of 'capabilities' more generally. What I take away from Sen's account is his focus on the relevance of human agency to human development. He claims agency is important not only because freedom

\footnotetext{
28 Sen, Idea of Justice, 287.

29 Sen, Inequality Reexamined, 56.

30 Amartya Sen, "Well-Being, Agency and Freedom: The Dewey Lectures 1984," The Journal of Philosophy 82.4 (1985): 203-204.

31 David A. Crocker, Ethics of Global Development: Agency, Capability, and Deliberative Democracy (New York: Cambridge University Press, 2008), 151.
} 
is itself essential for improving human lives but also because agency is constitutive of development. ${ }^{32}$ While Sen has mainly restricted his discussion to the realm of development ethics, I will be drawing on his insights and applying them more widely to all agents. Agency is incredibly important to all persons. Also, all societies can be improved in ways that make people's lives better. In the next section, I will outline more precisely the account of agency found in Sen and then show why it needs to be expanded to better capture all lives. It is at this point that the term 'development' will come to mean something different than what is typically meant by Sen and in development ethics discourse more generally. I am concerned now with the development, in terms of improvement, of all persons and their lives, not only those situated in so called 'underdeveloped' settings.

\section{Sen's Account of Agency}

According to Sen, "agency encompasses all the goals that a person has reasons to adopt, which can inter alia include goals other than the advancement of his or her own wellbeing." ${ }^{33} \mathrm{He}$ also explains that an agent is "someone who acts and brings about change, and whose achievements can be judged in terms of her own values and objectives, whether or not we assess them in terms of some external criteria as well." ${ }^{34}$ An action must be seen as effective, it must bring about change, or else it could not be seen as an agential act. If something should impede the agent's action, should it fail to be brought about, the individual's agency is being constrained. Also, if an agent should be discouraged by her circumstances from even attempting to make choices she has reason

\footnotetext{
${ }^{32}$ Sen, Development as Freedom, 4.

${ }^{33}$ Sen, Idea of Justice, 287.

${ }^{34}$ Sen, Development as Freedom, 19.
} 
to value; she is failing to express her agency. An agent's goals, objectives, and values should be those that she has reasons to have. One's actions must cohere with values and objectives that the agent has herself carefully considered. Since much of Sen's account of agency relies on agents' reasons to value certain beings and doings, I will turn to his account of rationality. I will also detail his discussion concerning the effect of social arrangements on agents. Finally, I will outline what Sen says about women's agency because he details specific factors he believes contribute to the expansion of agency. Namely, he recommends increasing independence and facilitating the expansion of reason through education to help combat limits on women's agency.

\section{$\underline{\text { Rationality }}$}

Sen offers criteria for what counts as objectives and goals that agents have reason to value. Since he is concerned with people's freedom to determine what they actually do have reason to value in the first place, he offers an account of how agents are to determine their own personal values. Sen claims that "it is the power of reason that allows us to consider our obligations and ideals as well as our interests and advantages." 35 There is a connection between what it is rational for an agent to choose and what an agent has reason to choose. ${ }^{36}$ Sen defines rationality as "a matter of basing...our choices on reasoning that we can reflectively sustain, and it demands that our choices, as well as our actions and objectives, values and priorities, can survive our own seriously undertaken critical scrutiny." 37 Our reason affords us the ability to critically reflect on the actions we have taken, or wish to take, as well as the validity of the

\footnotetext{
35 Sen, Development as Freedom, 272.

36 Sen, Idea of Justice, 180.

${ }^{37}$ Sen, Idea of Justice, 194.
} 
motivations for those actions. The choosing of certain values over others will be directed in part by our reason. Our values should be reflectively chosen and carefully considered. It is not every whim an individual happens upon that the capabilities approach is concerned to advance. Instead, its scope is restricted to a particular sort of value and choice. Sen explains that:

Having reason to do something ... demands that we investigate the reasons underlying the choice and consider whether the alleged reasons survive searching and critical examination, which one can undertake if and when the importance of such self-scrutiny is understood. The grounds of choice have to survive investigation based on close reasoning (with adequate reflection and, when necessary, dialogue with others), taking note of more information if and when it is relevant and accessible. ${ }^{38}$

Agents must recognize the importance of scrutinizing their own reasons through careful reflection. They must take into account new information and use this to help determine whether or not they have good reasons to sustain their values and pursue certain choices over others.

Sen's account of rationality is somewhat vague because he does not want to restrict 'reason' to the maximization of self-interest. This is because he believes people can have good reasons, ones that stand up to critical scrutiny, to possess goals, values, and objectives that are not purely self-serving. ${ }^{39}$ As he explains:

People's goals can go well beyond the single-minded promotion of self-interest only, and their choices may even go beyond the single-minded pursuit of their personal goals, perhaps moved by some concern for decency of behaviour, allowing others to pursue their goals as well. ${ }^{40}$

It is possible for people to possess good reasons to value goals that benefit both themselves and others. Sen claims that "we can reason our way towards following decent

${ }^{38}$ Sen, Idea of Justice, 180.

${ }^{39}$ Sen, Idea of Justice, 179.

${ }^{40}$ Sen, Idea of Justice, 194. 
rules of behaviour that we see as being fair to others as well." ${ }^{41}$ Rationality does not require that the only choices that stand up to critical scrutiny are those that benefit strictly the self. Choices that benefit the self by way of a concern for others can also stand up to critical scrutiny.

\section{Social Arrangements and Agency}

While rationality is one criterion for agency, individuals will require certain sorts of social arrangements in order to truly possess agency freedom. This is because social arrangements can significantly affect the reach of agency freedom. As Sen explains, "the freedom of agency that we individually have is inescapably qualified and constrained by the social, political, and economic opportunities available to us." ${ }^{\prime 2}$ The opportunities that are available to agents depend on which opportunities social arrangements have open to each individual. For social arrangements to be conducive to agency, freedoms must be formally extended to individuals. This requires taking steps such as formally guaranteeing rights and freedoms to individuals such that formal barriers to agential actions are removed. ${ }^{43}$ For instance, if playing a role in the shaping of public institutions is deemed valuable by an individual, she must be granted the extensive political freedoms required for her to do so. At a most basic level, freedoms will need to be formally guaranteed and protected by the state for agency to be possible.

From there, there are other factors Sen recognizes that can influence people's agency. For one, there is a complimentary relationship between social values and the

\footnotetext{
41 Sen, Idea of Justice, 192.

42 Sen, Development as Freedom, xi-xii.

43 Sen, Development as Freedom, 36-40.
} 
freedoms people have and choose to make use of. Sen highlights the strengths of his capabilities approach by explaining,

Such an approach... allows us to acknowledge the role of social values and prevailing mores, which can influence the freedoms that people enjoy and have reason to treasure. Shared norms can influence social features such as gender equity, the nature of child care, [etc].... The exercise of freedom is mediated by values, but the values in turn are influenced by public discussions and social interactions, which are themselves influenced by participatory freedoms. ${ }^{44}$

While an agent's ability to exercise her freedom is affected by shared norms, Sen argues that agents can use their freedom to influence those shared norms. Participatory freedoms are then incredibly important in Sen's account as they provide a vehicle for agents to participate in the public discussions such that they can shape the prevailing norms and values that influence their lives. ${ }^{45}$ Without being free to participate politically, people would be powerless to take part in the processes that shape public values. This would seriously limit the enjoyment of further freedoms because people would be unable to alter any norms that stand in the way of further freedoms they seriously value that are not currently available to them. However, for this sort of system to work, people must be willing to make use of the freedoms to participate in public discussion when they are made available to them. As Sen explains "democracy does not serve as an automatic remedy....The opportunity it opens up has to be positively grabbed in order to achieve the desired effect. ${ }^{, 46}$ People must actually seize available political freedoms to have a hand in shaping broad social values through participation in public discussion concerning social values.

\footnotetext{
44 Sen, Development as Freedom, 9.

45 Sen, Development as Freedom, 152-153.

${ }^{46}$ Sen, Development as Freedom, 155.
} 
Sen develops the connection between freedom and social arrangements further by claiming that "individual freedom is quintessentially a social product." The freedom we individually have is created socially; it comes out of the social arrangements we all continuously participate in and can choose to shape throughout our lives. People must push for the continued expansion of the freedom to participate in constructing social arrangements so as to ensure the continued expansion of their effective expressions of agency. Recall that, in its simplest iteration, an agent is "someone who acts and brings about change, and whose achievement can be judged in terms of her own values and objectives. ${ }^{47}$ To have the broadest scheme of freedoms to allow the agent to act in as many of the ways she values as possible, she must attempt to shape the social world she lives in such that it can be more conducive to her own effective expression of agency.

On Sen's account, agents must participate actively in the structuring of their social worlds to ensure the maintenance and expansion of their agency in accordance with their own values and objectives. According to Sen,

There is a two-way relation between (1) social arrangements to expand individual freedoms and (2) the use of individual freedoms not only to improve the respective lives but also make the social arrangements more appropriate and effective. Also, individual conceptions of justice and propriety, which influence the specific uses that individuals make of their freedoms, depend on social associations - particularly on the interactive formation of public perceptions and on collaborative comprehension of problems and remedies. ${ }^{48}$

The agent, to improve their social situation, must participate in the improvement of that social situation through the use of whatever freedoms are already available to them. Of course, they may be influenced by the prevailing norms in terms of what they currently value. However, according to Sen, they maintain the power to alter such things if they

${ }^{47}$ Sen, Development as Freedom, 19.
${ }^{48}$ Sen, Development as Freedom, 31. 
choose to seize available political freedoms to improve social arrangements. As Sen discusses the need to allow everyone, even the less socially privileged, to participate in discussions regarding what is worth preserving socially, he claims that "there is a real need — for social justice—-for people to be able to take part in these social decisions, if they so choose[emphasis added]. ${ }^{, 49}$ It is left up to individuals to decide if they would like to participate in the discussions that create and modify existing social norms and values. It is possible for agents to choose not to participate, and for Sen, that is an acceptable choice to make.

\section{$\underline{\text { Sen and the Case of Women's Agency }}$}

I will now examine Sen's discussion of women's agency. Sen recognizes that women have systematically faced inequalities in terms of the resources made available to them and the ways they have been treated more generally. ${ }^{50}$ It is then especially important to focus on women's agency, in particular, for the overall improvement of women's lives in the face of their inequalities. He also argues that improvements in women's agency will have net benefits for all people as advances in certain aspects of women's agency have corresponded with improvements in well-being and agency freedom for people beyond the women themselves. ${ }^{51}$ Sen recommends focusing on certain axes of women's agency such as "women's earning power, economic role outside the family, literacy and education, [and] property rights" as they collectively add "force to women's voice and agency - through independence and empowerment." ${ }^{, 52}$ All of these avenues can decrease

49 Sen, Development as Freedom, 242.

${ }^{50}$ Sen, Development as Freedom, 190-191.

${ }^{51}$ Sen, Development as Freedom, 191-192.

${ }^{52}$ Sen, Development as Freedom, 191. 
a woman's dependence on others, which in turn would grant her greater freedom to make decisions that are truly her own. They would add force to women's voices and their effective expression of agency by allowing them to no longer be at the mercy of others.

He argues that earning an independent income will advance the social standing of women in their homes and in their societies. ${ }^{53} \mathrm{He}$ also claims that "outside employment often has useful 'educational' effects, in terms of exposure to the world outside the household...women's education strengthens women's agency and also tends to make it more informed and skilled." ${ }^{, 54}$ Sen argues that earning an income will grant a woman greater power to negotiate and make demands within relationships of unequal power. ${ }^{55}$ These are the relationships that tend to exist within the home, between husband and wife, but also between a woman and others in her life who have greater social power. The assumption is that earning an income would empower women within these relationships. Greater resources as well as access to education and information about the world would make it possible for women to distance themselves from those she would otherwise be dependent on for the means for survival. Sen hopes that this will allow women to be better able to further their own personal goals instead of being forced to only further the goals of others. It will thereby also help women to combat the systemic inequalities that are rampant within existing social arrangements. ${ }^{56}$

Sen recognizes that women's dependence on others is only part of what's at issue for women's equality. Women are also disproportionately burdened by dependents and Sen highlights the negative impact women experience from high birthrates. He explains

\footnotetext{
${ }^{53}$ Ibid.

54 Sen, Development as Freedom, 192.

${ }^{55}$ Sen, Development as Freedom, 194.

${ }^{56}$ Sen, Development as Freedom, 191.
} 
that "the adverse effects of high birthrates powerfully include the denial of substantial freedoms — through persistent childbearing and child rearing — routinely imposed on many Asian and African women. There is, as a result, a close connection between women's well-being and women's agency in bringing about a change in fertility pattern." ${ }^{, 57}$ In this way, finding ways to decrease birthrates would enhance women's agency by eliminating a source of limits on her freedom and well-being. With fewer children, women would have to devote less time to raising children and would have more time to pursue their own goals. ${ }^{58}$

According to Sen, women's education is one of the leading factors that contributes to greater agency and has an interesting connection to the number of children women end up bearing. He claims that there is substantial empirical evidence that demonstrates "the unwillingness of educated women to be shackled to continuous child rearing." ${ }^{59}$ It appears this may be the case because "education ... makes the horizon of vision wider, and, at a more mundane level, helps to disseminate the knowledge of family planning. And of course educated women tend to have greater freedom to exercise their agency in family decisions, including in matters of fertility and childbirth."60 The expansion of women's agency occurs primarily through the expansion of women's general independence and access to knowledge that can inform and empower her to choose. According to Sen, increasing women's independence and access to education will naturally lead to an increase in their effective expressions of agency.

\footnotetext{
57 Sen, Development as Freedom, 198.

58 Sen, Development as Freedom, 216-219.

59 Sen, Development as Freedom, 199.

${ }^{60}$ Ibid.
} 


\section{The Problems with Sen's Conception of 'Agency'}

In the previous sections I identified the main tenets of the capabilities approach and highlighted the particular relevance of agency to Sen's account. There are three main problems with Sen's account of agency. First, his account is focused on an account of rationality that is too constrained to encompass all the ways in which agents will decide to express their agency. Second, Sen's account is too individualistic: Sen fails to appreciate the thoroughly relational nature of human beings and, thereby, the relational nature of agency. Third, although he recognizes that social arrangements can impact available freedoms and use of freedoms, his account fails to offer insights into expanding agency in the face of oppression. Oppressive social arrangements make the effective expression of agency nearly impossible for certain members of society in a way that expanding freedom alone cannot remedy. I will highlight the main problems in the sections that follow. However, a full defense of my arguments against Sen will come in the chapters that follow.

\section{Problems with Sen's 'Rationality'}

The only internal faculty Sen considers relevant to an account of agency is rationality. In Chapter 2, I will argue that rationality is not the only faculty that matters for effective expressions of agency. As Sarah Clark Miller explains, “...being an effective agent in the world calls for more than rationality can offer." ${ }^{, 61}$ Rationality alone cannot allow an agent to achieve all that she values. This is because many of the personal goals and values people choose will require more than highly developed rational capacities to be achieved.

\footnotetext{
${ }^{61}$ Sarah Clark Miller, The Ethics of Need: Agency, Dignity, and Obligation (New York: Routledge, 2012), 75.
} 
There are times when agents will need relational and emotional skills and thereby agency must be characterized in terms of these added capacities as well. It is for these reasons that Sen's constrained use of rationality as the guiding force for agency is a mistake. The importance of expanding our understanding of rationality to include concern for relationships and emotions as well as an account of agency that includes more than the faculty of reason will be developed in Chapter 2 .

Sen construes rationality and the process of coming up with good reasons in terms of critical scrutiny, reflection, full information, and, at least in part, self-interest.

According to Sen, our deepest values should be those that can stand up to our own careful scrutiny. He claims that, "while rationality of choice can easily allow non-self-interested motivations, rationality does not on its own demand this....Rationality as a characteristic of choice behaviour rules out neither the dedicated altruist, nor the reasoned seeker of personal gain." ${ }^{62}$ On Sen's account, rationality does not require that agents focus on the needs of others; only that particular agents can come up with good reasons to do so. However, an agent will require other people to focus on her development in order to have become an agent at all. For agency to ever get off the ground in the first place, agents must be motivated by a concern for others. Those who care for us early in our lives must specifically be focused on our needs in place of their own in order to help us develop into agents at all. ${ }^{63}$ Relationships are therefore implicated in the development of reason and one can only come to exercise her reason through participation in relationships that are fundamental to its creation.

\footnotetext{
${ }^{62}$ Sen, Idea of Justice, 194-195.
}

${ }^{63}$ Miller, Ethics of Need, 24, 
Relationships are also implicated in the development of agents more generally. Agents do not only rely on others for the development of their rational faculties but also rely on others to care for them and help them to later grow into capable adults. It is impossible to support an agent's growth through the exclusive use of and focus on rational capacities. A child requires having her emotional and social needs met to develop her faculties properly and to become an effective agent. ${ }^{64}$ Most agents will come to value engaging in and maintaining meaningful relationships with other people. Whether these are relationships with family members, friends, or romantic partners, everyone has an interest in preserving relationships in their lives. This is another reason why supporting people's expressions of agency necessarily requires much more than a focus on what is rational. An agent who participates in a relationship will at times need to prioritize the needs of the other person to maintain that relationship. Certain choices will need to be made that disregard what traditional theory has tended to presume is the most rational option.

Sen also argues that an agent can be empowered to choose through education as it will inform one's rationality. While I do agree that education can help with the development and improvement of rationality, the process of teaching happens within relationships. Teaching others requires careful communication in the attempt to facilitate the transfer of ideas and knowledge from one person to the other. Even within institutional settings, education takes place through the relationship that exists between teacher and student. Education occurs not only in institutional settings but also within families as parents try to prepare their children for the rest of their lives. Education,

\footnotetext{
${ }^{64}$ Miller, Ethics of Need, 25-26 and 75-76.
} 
insofar as it is the process of spreading knowledge and transmitting information to agents, takes place within relationships between agents and will require skills beyond the purely rational to take place effectively.

Also, greater information is only one small part of the agency puzzle. It is true that people must be made aware of opportunities to be able to then choose to take them up. However, there is often much in the way of agents taking up available opportunities than simple knowledge of their existence. This is often the case because of the impact of oppression on agents (addressed more fully later in this chapter and later in this thesis). In consideration of all the problems I have identified with focusing on a constrained conception of rationality as the only faculty that matters for expressions of agency, Sen's preoccupation with rationality is certainly misguided when it comes to effectively expanding agency.

\section{$\underline{\text { Sen's Individualistic Focus }}$}

In discussing his book Development as Freedom, Sen explains that, "this work is particularly concerned with the agency role of the individual [emphasis added] as a member of the public and as a participant in economic, social and political actions (varying from taking part in the market to being involved, directly or indirectly, in individual or joint activities in political and other spheres.)" ${ }^{65}$ Sen's point of concern is particular individuals. It is the particular person who exhibits agency who has the power to affect the world as an individual through choosing to participate in different realms. However, the agent and the sum of all economic, social, and political actions undertaken by all agents are interconnected in a way that Sen does not fully appreciate. Individuals

\footnotetext{
${ }^{65}$ Sen, Development as Freedom, 19.
} 
do not just participate in broad networks of relationships; they are also themselves constituted by those relationships. The connection between particular agents and social structures goes much further than what Sen considers. I will explore this connection more fully in the next section and in Chapter 3. For now, I will look at the problems with conceiving of agents individualistically in more particular instances.

Sen considers agents to be capable of separating themselves from their relationships with other people. He considers agents individually; capable of critical scrutiny alone and determining their own values and goals alone. He recognizes that agents are located within societies comprised of other people but does not recognize how thoroughly these other people affect our ability to be effective agents. I will go on to argue in Chapter 2 that people are constituted relationally and therefore so too is their agency. It is impossible to consider the agency of an individual separately from her relationships with others because these relationships make agency possible, are relevant to the enhancement of agency, and will be inevitably tied to a variety of goals that agents have reason to value. Agents cannot be considered separate from their relationships with other people because they are thoroughly interdependent.

Throughout his discussion of women's agency, Sen stresses the importance of expanding independence and encourages women to separate themselves from others as a way to add force to their agency. For instance, recall that he claims "women's earning power, economic role outside the family, literacy and education, [and] property rights" collectively add “force to women's voice and agency—through independence [emphasis added] and empowerment.. ${ }^{, 66}$ He specifically recommends factors he sees as directly

\footnotetext{
${ }^{66}$ Sen, Development as Freedom, 191.
} 
conferring greater independence to women to enhance their agency. Sen's preoccupation with independence exemplifies his failure to capture the ways people may choose to be in the world that prioritizes relationships. It also signals a failure to recognize the need people will have for the help of others to realize their varied goals and values. People do not thrive independently, in the way Sen presumes, but instead thrive relationally, in connection with others.

Sen claims that "greater freedom enhances the ability of people to help themselves [emphasis added]. ${ }^{967}$ Sen assumes freedom can empower individuals to help themselves and he recommends expanding freedom as he views it as a vehicle for people to separate themselves from others through the expanded independence that greater freedom grants agents. However, human beings are fundamentally vulnerable and interdependent. ${ }^{68}$ An individual may require the help of others to 'help themselves' even if extensive freedoms have been secured. People will also need support from those with whom they are in relationship to establish, maintain, and restore their agency. ${ }^{69}$ Relationships play a large role in the effectiveness of agency. This is true at differing levels: in terms of the broad relationships people participate in and in terms of the particular personal relationships within which people exist. There is very little about the individual that is truly individual. Sen's focus on the agent as an independent individual strips away characteristics that are fundamental to the agent. Expanding an agent's freedom cannot always confer improvement in human lives because there are many things that agents can never be

\footnotetext{
${ }^{67}$ Sen, Development as Freedom, 18.

${ }^{68}$ Miller, Ethics of Need, 4-5.

${ }^{69}$ Miller, Ethics of Need, 17.
} 
genuinely free from: namely, the impact of the broad network of relationships within which they are situated.

The 'unchosenness' of our relational context also causes serious problems for Sen's account. He relies on the expansion of freedom to solve problems of inhibited agency. However, freedom can never be fully extended in the realm of relationships. What I mean by our relationships being unchosen is that our context largely determines who we come into contact with. Yet, we are mostly unable to control what our context is or who else is party to that context. We are born into a place we did not choose, to parents we did not choose, and have neighbours we also could not choose. While this may appear to run counter to the possibility of agency, it is simply a fact about human beings. This inability to choose everything about the way our lives go does not make it impossible to be an agent. It is only that individuals are forced to navigate this truth of relationships when expressing their agency.

As it stands, Sen's conception of 'agency' excludes the facts of relationship and interdependence and the effects these facts have on the human experience from the beginning. Individuals cannot be considered separately from their relationships with other people as their attachments to others and embedded positions within a broad network of relationships are realities that particular agents will be unable to separate themselves from. This fact of relationality inevitably affects expressions of agency. An enriched account of agency would have to then include these features of human beings at the start. This is the type of account of agency I will be developing in Chapter 2 . 


\section{The Limits Imposed by Oppressive Relationships}

Sen's individualistic conception of agents leads to even bigger problems when considering the broad network of relationships in which all agents are embedded. This network of relationships thoroughly impacts each agent in a variety of ways and at differing levels. ${ }^{70}$ There will be many cases in which these relationships are not to the benefit of all those within them. In particular, Sen does not account for oppressive relationships marked by inequalities of power between members at both personal and broad levels. Christine Koggel argues that Sen does not recognize those relationships that many can be "powerless to exit, challenge, or change." ${ }^{.71}$ People can be incapable of leaving relationships that cause them harm due to others restricting them from doing so or because leaving those relationships would actually cause greater harm. ${ }^{72}$ These relationships can impose strict restrictions on the freedom an individual possesses because they "determine the resources one gets, the perceptions of what one deserves or is capable of, and the power that one has to make changes." ${ }^{, 73}$ Since it may be difficult or even impossible to alter these relationships for some, these individuals cannot be effective agents according to Sen as they are not pursuing options that they truly have reason to value. Those options that they do have reason to value - ending the bad and oppressive relationships - are not within the realm of options they are able to pursue. It will often be the case that people will be unable to alter the oppressive relationships within which they exist that are limiting their ability to be agents no matter the number of

\footnotetext{
${ }^{70}$ Christine Koggel, "A Relational Approach to Equality: New Developments and Applications," in Being Relational: Reflections on Relational Theory and Health Law, ed. Jocelyn Downie and Jennifer J. Llewellyn (Vancouver: UBC Press, 2012), 70-74.

${ }^{71}$ Koggel, "Relational Approach to Equality," 71.

72 Khader, Adaptive Preferences, 130-131.

73 Koggel, "Relational Approach to Equality," 72.
} 
opportunities that are extended to them. Expanding freedom cannot alone grant agents the power to navigate the impact of relationships on their expression of agency.

Susan Sherwin argues that oppression inhibits expressions of agency by discouraging actions that could dismantle the social understanding responsible for the oppression in the first place. ${ }^{74}$ People are often oppressed for reasons beyond their control. Reasons could include such arbitrary traits as their gender, class, and race. It is determined that due to certain qualities, there is something less worthy about the oppressed persons such that holding them back or limiting their opportunities is sometimes considered acceptable within a given social context. ${ }^{75}$ This status of the oppressed person is determined by others. One does not get to choose her oppression. It is others who have decided on her behalf that she is a member of an oppressed group. ${ }^{76}$ So, from the start, there is clearly a severe limit on the individual's ability to act as an agent: she cannot even decide her fate in these cases. Membership in an oppressed group limits the feasible options available. This is because, as Sherwin notes, there are social punishments for attempting to challenge the oppressive norms while the maintenance of those norms is often rewarded. ${ }^{77}$ In these cases, although challenging the social structure appears to be required for enhancing one's agency according to Sen, it is difficult and often impossible for those most interested in making the changes to actually do so. Those who refuse to conform to the socially acceptable ways of being may suffer further isolation, ostracism, and violence even beyond the initial impositions of oppression. ${ }^{78}$

\footnotetext{
74 Sherwin, "Relational Autonomy and Global Threats," 17.

75 Iris Marion Young, Justice and the Politics of Difference (Princeton: Princeton University Press,, Politics of Difference), 40-43.

${ }^{76}$ Young, Politics of Difference, 43 and 46.

77 Sherwin, "Relational Autonomy and Global Threats", 17-18.

78 Ibid and Young, Politics of Difference, 48-63.
} 
Instead, maintaining one's own oppression is the best option which inevitably restricts one's agency completely on Sen's account. Sen's account of agency cannot adequately accommodate the impact of oppression and instead would dismiss the idea that oppressed persons' are capable of expressing agency effectively.

This is even more troubling when considering Sen's discussion of participation and the design of collective social values. He argues it should be left up to members of a society to determine for themselves their collective social values. ${ }^{79}$ He also argues that the determination of what is socially valuable should occur through agents' participation in public discussions. ${ }^{80}$ People can offer ideas and opinions that differ from the accepted norms when desiring changes to what is commonly perceived as normal or valuable. ${ }^{81}$ However, those who are adversely affected by certain social values will be powerless to participate in meaningful ways to change them. It is simply impossible for those with inhibited agency to adequately participate in public discussions in ways that would cause social norms to change. Oppressed persons cannot meaningfully participate in the process of changing broad social valuations because the broader society is structured such that the oppressed are pressured to accept and cannot challenge their oppression. They are limited from participating both explicitly, through institutionalized structures of oppression that form real barriers to their participation, and implicitly, through the broader norms that govern their behaviour. The full range of limits imposed by oppression on agents and the ways of managing these will be discussed more fully in Chapters 3 and 4 . What is

\footnotetext{
${ }^{79}$ Sen, "Dewey Lectures", 204.

${ }^{80}$ Sen, Development as Freedom, 241-242.

${ }^{81}$ Sen, Development as Freedom, 30 and 152-153.
} 
important to note is that expanding freedom for oppressed agents will not necessarily allow them to express 'agency' as Sen construes it.

While Sen does recognize that women face greater inequalities in the world than men, he does not fully appreciate the effects of oppression on women and this leads him to problematic conclusions for the expansion of women's agency. For instance, he suggests that women who are already facing oppression should engage in paid labour outside the home in order to make their agency more effective. ${ }^{82}$ However, due to the nature of oppression, this would likely cause greater harms to women instead of advancing their agency. This is because earning an income does not change the structural system of equalities women face at all levels of relationship. Engaging in paid work does not change the assumption that a woman's needs are less pressing than a man's. It does not mean that the extra resources will necessarily go to benefiting women. It is far more likely — considering the broad network of relationships that continuously reinforce and maintain women's inequalities at various levels - that those resources will instead be transferred to men and they will continue to benefit men at an even greater cost to the women who actually need them. It also adds pressure on women to engage in additional work. Engaging in work outside the home does not change the fact that women are still expected disproportionately to provide care within the home. Further, in a society that oppresses women, women will likely face added oppression in the workplace. Instead of disrupting systems of oppression, Sen's recommendation can intensify women's oppression within a broad network of relationships that is itself oppressive.

\footnotetext{
${ }^{82}$ Sen, Development as Freedom, 192.
} 
This relates back to my earlier concerns with Sen advocating access to education in the face of constrained agency. He assumes education will provide women with a broader horizon and therefore more information to reassess her reasons and select from a broader range of possible beings and doings. ${ }^{83}$ However, when an agent gains knowledge of an opportunity, it does not guarantee that she has real access to that opportunity. For example, Sen notes that the education of women appears to correlate with lower birth rates. ${ }^{84} \mathrm{He}$ claims that educated women seem to be unwilling "to be shackled to continuous child rearing" because "education ... makes the horizon of vision wider, and, at a more mundane level, helps to disseminate the knowledge of family planning."${ }^{.85}$ However, for women to feel free not to have children, it may be required that we change broader norms concerning what it means to be a woman as opposed to requiring changes in the lives of particular women. If motherhood is inherently tied to a woman's worth, this social norm will put pressure on women to continue to choose to have children. Regardless of her level of education, a woman may feel as if choosing not to have any more children is not an available option because of the implications that choice would have on her identity as a good mother and on her worth as a woman. The social understanding of 'motherhood' can then serve to inhibit her ability to express her agency. Educating women will not disrupt the broad social norms imposing behaviour on those women. Broad social values shape the information educational institutions impart on their students as well as the way they transmit this information. Therefore, educational institutions may actually serve to reinforce broader social values as those values will have

\footnotetext{
83 Ibid and 199.

84 Sen, Development as Freedom, 198-199.

85 Sen, Development as Freedom, 199.
} 
structured the ways those institutions have been organized and the information deemed relevant to the education of others.

Since oppressed persons will often be powerless to challenge their oppression through particular, individualized agential acts, the solution must come from somewhere else. Oppressed agents will not be able to change oppressive structures alone due to the nature of oppression. They will also be restricted from participating in the public discussions through which Sen argues these social values are determined and can be changed. Oppressed persons are then restricted from being agents in multiple ways that Sen's account cannot address.

\section{Conclusion: The Need for Recognition of Relationality}

Sen does not adequately acknowledge the thoroughly relational nature of agents and the conditions under which they express their agency. Sen defines agency in terms of a constrained account of rationality and argues that greater independence and freedom will aid in the expansion of agency. This misses out on the broad networks of relationships that affect particular relationships within which people participate in ways that can restrict people's freedom to act as effective agents. The broad network of relationships does not simply affect the availability of opportunities or our understanding of what is valuable but structures people's lives in ways they can be powerless to alter. All people will have their agency affected, in some way, by the presence of others in their lives. Since there are many factors beyond the particular individual that make her agency possible and effective, an account of agency must be expanded beyond the rational and the individual. I will offer an expanded account of agency that is sensitive to the relational nature of agents in the chapter that follows. 


\title{
Chapter 2
}

\section{An Expanded Account of Agency}

\author{
$\underline{\text { Introduction }}$
}

In Chapter 1, I identified problems facing Sen's account of agency. He does not effectively account for the fundamentally relational nature of human lives and the complex ways this fact will inevitably affect human beings, their values, actions, and, most importantly, their agency. This chapter is focused on enriching the definition of agency provided by Sen such that it can be sensitive to some of the problems raised against his account in Chapter 1. In particular, the expanded account of agency developed here will deal with the problematic emphasis Sen places on rationality. I will draw on Sarah Clark Miller's expanded account of agency to help begin to fill out the concept of 'agency'. Miller suggests that agency should be characterized in terms of the rational, relational, and emotional abilities of human beings. This handles my criticism that Sen's account treats rationality as the only faculty relevant to agency.

Miller's account depends on the moral power to care in the face of human beings' interdependence and experience of fundamental needs over the course of a life. The human capacity to offer care to others motivates Miller to include relational and emotional abilities in her account of agency. She argues that these abilities are required for the provision of good, dignifying care. I will outline what, more specifically, is required for providing good care and its connection to agency according to Miller. After a discussion of care, I will provide Miller's description of the abilities of rationality, relationality, and emotionality. Miller argues that the abilities of rationality, relationality, and emotionality are especially important because they are required to provide good care 
to others who need it. She also argues they are relevant because agents will choose to use these skills to realize their specific goals and values. Miller claims that individuals will draw on the different abilities at different times in their life to realize their own agency goals as well as to help others to advance their agency goals.

Miller's account is not without its problems. First, I will argue that, despite her consideration of the abilities of relationality, emotionality, and a concern for others, Miller's account is still too individualistic. Miller focuses on agents in particular, and what specific agents owe one another. I believe that Miller's individualistic focus comes out of her dependence on the duty to care to ground her account of agency. I will argue that the basis for an expanded account of agency should be the thoroughly relational nature of human beings. I will offer an account of the relational nature of human beings as the basis for an expanded account of agency in place of Miller's duty to care.

I will also deal with my contention that Sen's account of rationality is too constrained. I will argue rationality, relationality, and emotionality are inextricably interconnected both in the establishment of these skills and in their practice. The three abilities will often be tied up one in another when people engage them to affect their agency. This is because the thoroughly relational nature of agents implicates relationality and emotionality as relevant to the determination of good reasons for agents.

I will then argue, in part in this chapter but more fully in Chapter 3, that Miller's account must be supplemented with a relational account of autonomy. This is because an account of agency cannot fully address the relevance of the broader network of relationships through which oppression is generated. An expanded account of agency must be paired with a relational account of autonomy to fully account for all the factors 
that contribute to the establishment, restoration, and maintenance of agency. In this chapter, I will signal the points at which Miller's account cannot accommodate the concern for the effects of oppression on agents and discuss those more fully in Chapter 3.

\section{Miller's Expanded Account of Agency}

Miller defines 'agency' as “...the ability to achieve some manner of results in the world, to affect change in accordance with one's volition, and to maintain the ability to carry out projects (often self-determined) in a surrounding environment." $" 86$ To be an agent is to be able to act unimpeded in the world and in accordance with our own values. In order to be able to do this effectively, Miller claims, we will require the development of certain abilities that give us the skills needed to actually carry out our specific self-determined projects. These abilities are rationality, relationality, and emotionality. ${ }^{87}$ Her account can be considered 'expanded' because it includes more than the human capacity for rationality. Traditional accounts tend to describe an agent as a hyper rational being that acts based on what is most rational for her ${ }^{88}$ Miller argues that rationality is but one characteristically human ability that plays a role in effective agency. Relationality and emotionality are also important human abilities that are often necessary for the effective expression of agency. Her account of the omnipresence of fundamental needs and the persistence of vulnerability prompts her to defend these abilities. She defines human beings in terms of their continuous need for others: we are born into the world incapable of surviving without the care of others and continue to need others to help us secure our

\footnotetext{
${ }^{86}$ Miller, Ethics of Need, 24.

87 Ibid.

88 Annette C. Baier, "The Need for More than Justice," Canadian Journal of Philosophy 13 (1987): 41-56; Sarah Clark Miller, "Cosmopolitan Care," Ethics and Social Welfare 4.2 (2010): 145-157; Miller, Ethics of Need, 2-6.
} 
goals and values throughout the rest of our lives. ${ }^{89}$ This fact of inescapable need generates a moral duty to care due to the harms experienced by people experiencing fundamental needs. The duty arises not only because this need is constant but also because failure to respond to the needs of others would cause great harms to their agency. ${ }^{90}$ Miller's account is focused on the connection between agency and a duty to care. Harms to agency caused by the presence of fundamental need are the morally salient harms that generate Miller's duty to care.

\section{Fundamental Need and Harms to Agency}

Miller's account of agency begins with the presence of fundamental needs. She characterizes fundamental needs as those that:

Others must meet in order for a person (1) to avoid significant harm; (2) to be able to choose and carry out action in the world; and (3) to be self-determining. Fundamental needs arise in situations or conditions in which the agency (or the potential for agency) of an individual is acutely endangered. They are fundamental in that such needs must be met for an individual to develop, maintain, or reestablish agency. ${ }^{91}$

Fundamental needs are characterized specifically as those that cause harms to agents through the limiting of their ability to effectively express their agency. They are also those that, due to the harms to agency they cause, agents will require the help of others to meet. Human beings are vulnerable, they will consistently experience fundamental needs throughout their lives and thereby continuously require help from others in order to develop, maintain, and establish their agency. As Miller explains, "during the span of a finite human life, many different fundamental needs will arise, and agents will require the

${ }^{89}$ Miller, Ethics of Need, 24 and 37.

${ }^{90}$ Miller, Ethics of Need, 23.

${ }^{91}$ Miller, Ethics of Need, 4. 
assistance of others to help respond to those needs." ${ }^{92}$ Everyone will experience fundamental needs that call for another's response to be met effectively. These needs are so pressing precisely because they entail serious harms to agency.

The sorts of needs Miller is referring to are: "the need for bodily integrity, shelter, and nutrition, as well as the perhaps less obvious need for social inclusion and emotional attachments. ${ }^{93}$ These kinds of needs will severely inhibit the effective expression of agency and these needs demand attention from others. Miller argues that "our mutual and inevitable interdependence gives rise to a duty to care for the fundamental needs of others. ${ }^{.94}$ Miller identifies the process of recognizing and addressing the needs of others as that of care. However, Miller claims that "the duty to care does more than obligate agents to respond to others' needs; it requires that the nature of their response be both respectful and caring." ${ }^{95}$ In the next section, I will lay out Miller's account of care. A complex set of skills are required for meeting people's fundamental needs effectively and in a way that respects the agency of the one experiencing fundamental need. In particular, Miller argues that the provision of appropriate care will require the abilities of relationality, emotionality, and rationality.

\section{The Provision of Care}

Miller describes caring as "the process of responding to another's needs by understanding their self-determined ends, adopting those ends as one's own, and advancing them in an

\footnotetext{
92 Miller, Ethics of Need, 17.

${ }^{93}$ Miller, Ethics of Need, 4.

94 Ibid.

${ }^{95}$ Miller, Ethics of Need, 5.
} 
effort to cultivate, maintain, or restore their agency." ${ }^{96}$ The human capacity to care for others by adopting their ends as our own is a "distinguishing moral power" in a way similar to how many conceive of our capacity for reason. ${ }^{97}$ People will require a variety of aptitudes to effectively meet the needs of others "including cognitive abilities, practical skills, and general attitudes toward those in need." ${ }^{98}$ Providing good care, what Miller refers to as "dignifying care", is not a simple task. ${ }^{99}$ Miller claims carers must engage in certain care related practices such as "increased abilities of moral perception, emotional attunement to the one in need, awareness of power relations..., cultivation of the self-determination of the one in need, and caring for others as situated moral patients. ${ }^{100}$ Attentiveness must be paid to the person experiencing fundamental need; one must be able to perceive the presence of need in the other person in the first place to ever be capable of meeting such need. ${ }^{101}$ This will often require tabling one's own needs in order to pay close attention to what others may require. ${ }^{102}$ The one providing care must work hard to correctly identify the need that is present and come up with a method of meeting that need that matches the broader goals and values of the agent in need, effectively meets the existing need, and respects that agent's dignity. ${ }^{103}$

People will often be called on throughout their lives to provide care to those experiencing need; to do so effectively will require relational and emotional abilities. ${ }^{104}$

\footnotetext{
96 Miller, Ethics of Need, 79.

${ }^{97}$ Miller, Ethics of Need, 77.

98 Miller, Ethics of Need, 88.

99 Miller, Ethics of Need, 83-84.

100 Miller, Ethics of Need, 88.

101 Miller, Ethics of Need, 89

102 Joan C. Tronto, Moral Boundaries: A Political Argument for an Ethic of Care (London: Routledge, 1993), 128.

103 Miller, Ethics of Need, 61-64.

104 Miller, Ethics of Need, 78-79.
} 
The person providing care must have knowledge of the other person such that they can identify her ends and determine what ways are best for advancing them from the perspective of that other person. This requires the ability to have meaningful relationships with others as this allows one to have the relevant knowledge needed to provide effective care. The carer must also be skilled in terms of emotion — having appropriate emotional responses and being able to identify the feelings of others effectively — to cultivate the other's agency in the right sort of way. Miller argues that reason will also be implicated in the accurate perception of the needs of the other as well as in the carer's determination of effective and dignifying ways of meeting another's needs. ${ }^{105}$ One must be able to discern, in part through the use of reason, the particular response called for by the one in need based on what that person truly needs in the given situation and context. Of course, what is reasonable in terms of the provision of care is heavily affected by what is emotionally and relationally salient in the given case. What one reasonably requires in order to have her needs met may only be discoverable through the use of emotionality and relationality along with rationality. Since human beings will require care throughout their lives and providing care is a challenging practice that calls for developed relational and emotional abilities, these abilities deserve recognition.

\section{Relationality, Emotionality, and Rationality in Connection with Agency}

A person will require relationality, emotionality, and rationality "to establish, maintain, or restore agency" in those experiencing fundamental needs; in other words to provide dignifying care to agents who require it. ${ }^{106}$ This is, in part, what prompts Miller's

${ }_{106}^{105}$ Miller, Ethics of Need, 78. 
inclusion of these three abilities within her account of agency. ${ }^{107}$ Relationality, emotionality, and rationality are required for the adoption and furtherance of another's goals and values in part because specific agents may themselves choose to draw on these plural abilities to reach their own agency goals. Recall Miller's definition of 'agency': "the ability to achieve some manner of results in the world, to affect change in accordance with one's volition, and to maintain the ability to carry out projects (often self-determined) in a surrounding environment. ${ }^{" 108}$ Acting in these ways, for oneself as well as when providing dignifying care to establish, maintain, and restore the agency of others, will require relationality, emotionality, and rationality. Insofar as people will express their agency through these skills, they may need to be supported or used by those offering care.

Miller uses an example to make her case for the relevance of emotionality and relationality. She asks us to imagine a child provided with every advantage to develop their rationality but who lacked any help in developing any other abilities. ${ }^{109}$ Even if provided every possible outlet for rational development, it seems the child will be missing out on a lot if she does not have the chance to advance any of her other skills. ${ }^{110}$ Miller argues that to focus on independence and rationality requires abstracting from the actual lived experiences of human beings as well as their unique perspectives on what is truly valuable in life. She claims that "such a degree of abstraction willfully ignores the embeddedness of moral agents in at least two significant respects: first, as persons

\footnotetext{
107 Miller, Ethics of Need, 78-79; 88.

108 Ibid.

${ }^{109}$ Miller, Ethics of Need, 47.

${ }^{110}$ Miller, Ethics of Need, 76.
} 
situated in a nexus of human relationships and second as persons with specific identities."111

Miller says only a few things explicitly about relationality. What is clear is that it comes out of the ability human beings have to care for one another and so must be related to our connection with others and the process of adopting another's ends as our own. To do this well requires some sort of relational ability; some way of relating to others and existing in relationship with them. She treats 'relational' as synonymous with 'social' and claims that those who are relationally attuned "may demonstrate their agency by actively fostering positive forms of human emotional involvement. [emphasis added]"112 Our relationality then must have something to do with our sociability, our disposition towards getting involved in others' lives, and our tendency to nurture positive emotions in those relationships. According to Miller, relationality then has some connection to emotionality. Miller claims relationality is important to agency and care without offering a substantial account of what it actually is as a capacity.

Miller has recommended an expansion of agency not only in terms of relationality but also in terms of emotionality. Emotionality, like relationality, comes out of our moral power to provide care to others. Miller explains that "good care often involves emotional attunement to those in need and emotional involvement in the situation of need." ${ }^{113}$ Emotionality can also play a role in individual expressions of agency. As Miller explains "thriving agents may engage in various forms of affective response, as they express

\footnotetext{
111 Miller, Ethics of Need, 149.

112 Miller, Ethics of Need, 76.

${ }^{113}$ Miller, Ethics of Need, 90.
} 
themselves to others and perceive their emotional landscape. ${ }^{\not 14}$ However, it is primarily carers who must constantly engage emotionality: choosing how best to emotionally respond to their environments and working towards accurately perceiving the emotions of those they are in relationships with to better understand how to meet others' needs. Miller claims that "effective agents have a variety of forms of emotional response at their disposal, exercising their abilities to properly perceive and respond to the emotions of others. Agency also includes a caring component, one with a significant emotional dimension." ${ }^{115}$ The development of effective agency will require addressing the emotionality of agents. However, Miller does not really explain what exactly 'emotionality' is. She claims it is important for agency, care, and has something to do with perceiving the emotions of others to be a more effective carer. She does not explain specifically how it is an agent can develop this skill or what constitutes strength in emotionality when it is not directly tied to the provision of care. I will offer a more extensive account of emotionality on these fronts in the next section as well as a better account of relationality.

\section{Miller's Account in Summary}

Miller's account of agency is tied to a duty to care in response to the presence of fundamental needs in human lives. There exists a duty to care for others because a failure to meet a person's needs will result in that person's agency being inhibited which is the harm that calls for the duty to care in the first place. ${ }^{116}$ An agent will require the abilities of relationality and emotionality, beyond just rationality, to address the fundamental

114 Miller, Ethics of Need, 76.

115 Miller, Ethics of Need, 24.

${ }^{116}$ Miller, Ethics of Need, 47. 
needs of others. This is because providing dignifying care can be challenging and will require a diverse set of skills to be done well. Miller tends to discuss relationality, emotionality, and rationality as connected in virtue of their relevance to the provision of good care ${ }^{117}$ The duty to care is what she employs to justify the relevance of these abilities to her account of agency. Miller's account then handles one of my criticisms of Sen: it is not cashed out solely in terms of rationality. Miller argues that rationality is not the only morally relevant human capacity and that relationality and emotionality are similarly relevant to an account of agency. ${ }^{118}$ However, Miller's account does not address all of my criticisms of Sen. I will identify the problems with Miller's account of agency next.

The Problems with Miller's Account of Agency: Not Relational Enough Miller's discussion of relationality and emotionality hinges on their relevance to a duty to care rather than their relevance to agency more specifically. My project is concerned with the expansion of people's ability to express their agency effectively. While it is true that this will in part require others to respond to our fundamental needs as they arise, it will also require the advancement of rational, relational, and emotional skills. Miller does not fully address the thoroughly relational nature of agents and the ways in which this fact will completely impact agents, their effective expressions of agency, and the barriers to their effective expression of agency. Miller's account, although less individualistic than Sen's, is still too individualistic; this generates her failure to fully recognize the impact of the broader network of relationships and oppression on agents.

\footnotetext{
${ }_{117}$ Miller, Ethics of Need, 73-96.

${ }^{118}$ Miller, Ethics of Need, 77.
} 
I will offer a relational account of the self as an alternative basis for the importance of the interconnected abilities of rationality, relationality, and emotionality as the individualistic aspects of Miller's account stem in part from her focus on a duty to care. Since relationships condition the agent and structure the world in which she is expressing her agency, agents will require the skills of relationality, emotionality, and rationality taken together to express their agency effectively within their thoroughly relational contexts. A relational conception of the self will also demonstrate the ways in which oppression will affect particular agents as the particular relationships within which agents are embedded are themselves structured by the overarching, broader network of relationships. While the problems with individualism on the level of particular agents will be addressed through my discussion of the relational nature of the self, I will argue that the impact of oppression cannot be handled through an account of agency alone.

\section{A Relational Conception of the Self}

It is a fact about human lives that our relationships with other people are relevant and important to us. Not only this, but these relationships have a large impact on the course of our lives and our ability to act as an effective agent. Human beings require dignifying care early in their lives to develop the capacities required to become agents and these capacities will be necessary for the continued effectiveness of a person's expression of agency. Relationships have an immense impact on the agent. As Françoise Baylis explains "persons are interdependent beings, and so it is that a person's identity (including her traits, desires, beliefs, values, emotions, intentions, memories, actions, and experiences) is informed by her personal relationships - relationships characterized by 
varying degrees and kinds of intimacy and interdependence." ${ }^{119}$ The way that a person is, the personality she develops, her preferences, values, and the narrative she forms of herself are all informed and affected by her relationships with other people. The selfconcepts of agents, which will likely inform their expressions of agency, are drawn from their relationships with other people.

Jennifer Nedelsky claims that "many people will see their personal relations with friends and intimate partners as formative.....Many people can see how these relational patterns have shaped the persons they have become." ${ }^{120}$ These formative relationships "range from intimate relations with parents, friends, or lovers to relations between student and teacher, welfare recipient and caseworker, citizen and state." ${ }^{, 121}$ We are all able to recognize the impact people, beyond merely our parents, have had in the resulting selves we come to develop. Relationships are then formative insofar as they influence us in fundamental ways. At a personal level, our interactions with proximate others shape and form us continuously as we navigate within networks of relationships throughout our lives.

As personal relationships affect agents individually, these relationships are structured by the overarching, broader network of relationships that make up the social conditions of any given context. Nedelsky claims, when discussing personal relationships, that "these relations, in turn, will be shaped by wider patterns of relationship, such as heterosexual norms, gender norms, and gendered division of

\footnotetext{
${ }^{119}$ Françoise Baylis, “The Self in Situ: A Relational Account of Personal Identity,” in Being Relational: Reflections on Relational Theory and Health Law, ed. Jocelyn Downie and Jennifer J. Llewellyn (Vancouver: UBC Press, 2012), 109.

120 Jennifer Nedelsky, Law's Relations: A Relational Theory of Self, Autonomy, and Law (New York: Oxford University Press, 2011), 20.

${ }^{121}$ Nedelsky, Law's Relations, 19.
} 
caretaking work." ${ }^{122}$ Baylis also recognizes the relevance of those broader relationships as she claims "no less important are the public interactions (social, cultural, and political) that help structure a person's account of herself and her place in the world." ${ }^{, 123}$ These are the relationships that exist beyond the level of personal. They are the broader systems of relationships that structure conceptual frameworks through which large groups of people view the world. This is at the level of social norms and social values that an entire society can embody, both implicitly and explicitly, throughout the interactions that comprise it. A society is just a broad web of varied relationships; those that are not only personal but also institutional, national, and global. ${ }^{124}$ There exist certain norms concerning which interactions are appropriate and acceptable within relationships between individuals who are embedded in this broader network of relationships.

Broadly accepted values and norms will affect agents as they are pressured to accept and sustain them through their effects on the particular relationships within which they participate. This will be true even in the case of oppressive norms that impose problematic values and place severe limits on agents. Oppression will affect which expressions of agency are appropriate for which people and often in problematic ways. Social meanings will be affixed to members of specific social groups and the people within those groups will be shaped by meanings associated with their social groups. ${ }^{125}$ For those who face oppression, their social group affiliations will inform their understandings of themselves as well as others' perceptions of them. Examining different levels of relationships can reveal that oppressed agents will be pressured to express their

\footnotetext{
122 Nedelsky, Law's Relations, 20.

123 Baylis, "The Self in Situ", 109.

124 Koggel, "Relational Approach to Equality," 65.

125 Young, Politics of Difference, 44.
} 
agency in ways that maintain the oppressive norms governing those relationships. I will offer more substantial arguments for this position in Chapter 3.

Relationships are relevant to agents in terms of their self-concepts, the opportunities reasonably available to them, and the values they have reason to adopt. Each agent is situated within a diverse web of relationships. People participate in numerous relationships and these relationships are quite important to those who exist within them. This means that agency will be fundamentally affected by relationships with other people because agents themselves are so affected by them. Not only this, but broader social norms structure the relationships that all persons are in. Miller's account does not explicitly note the complex and thorough impact of the networks of relationships in which all agents are situated.

\section{Miller Explicitly Focuses on the Individual}

Despite the relational nature of selves, Miller attempts to bracket the discussion of the broad network of relationships and chooses instead to focus on individuals and their particular moral obligations to other specific individuals. Miller explicitly states that "in my discussions of the duty to care, I have primarily considered interactions between individuals, namely caretakers and those in need. While not maintaining an exclusive focus on the individual level, it is both a starting point and guiding concern of this work." ${ }^{126}$ However, without a full appreciation of the thoroughly relational nature of individuals, an account that focuses exclusively on an individual's moral obligations will be missing many important factors. Miller also misses the connection between the social and political level and specific moral obligations. She claims that "the duty to care begins

\footnotetext{
${ }^{126}$ Miller, Ethics of Need, 138.
} 
from the perspective of ethical obligation for individual moral agents, although it certainly has political and social ramifications." ${ }^{127}$ The problem here is that individual moral agents are themselves conditioned by the social and political structures in place. The political and social level significantly conditions the ethical obligations of individual moral agents in a way that makes it impossible to separate out the discussion of the social and political without missing many important details affecting individual moral agents.

Miller recognizes that not everyone will agree with her decision to focus on the individual moral agent as a guiding concern. She explains that:

While ethical arguments tailored to the individual level are not representative of all possible tacks one might take on any given ethical issue, they constitute one vital approach. Ethical inquiry at this level on the topic of needs is both necessary and legitimate. Moreover, in beginning this book from the point of view of individual moral agents making decisions about how to act and how to live, I aim to place my work in conversation with a longstanding tradition in ethical theory of approaching human need and responses thereto on the individual level. ${ }^{128}$

However, individual moral agents make decisions about how to act and how to live in thoroughly relational contexts. They will also be continuously affected by their relationships with other people in deciding how it is they want to act and live. A focus on the individual is only one of many important aspects that must be addressed in order to accurately account for agency. It may be necessary to address the individual level insofar as individuals do matter. Although, without an appreciation for the thoroughly relational nature of human beings and the ways in which the broad network of relationships structures their lives, so much will necessarily be missing from an account that is exclusively focused on individuals. There is more to the establishment, maintenance, and

${ }^{127}$ Miller, Ethics of Need, 130.

${ }^{128}$ Miller, Ethics of Need, 138. 
restoration of agency than Miller's individualistic duty to care can accommodate by itself.

\section{Expanding Miller's Account of Agency: The Fact of Relationality}

I will expand Miller's account even further to accommodate the fact of relationality more fully. However, there will be a point at which expanding Miller's account cannot address all the ways relationships affect agents. This is so in the realm of the broader network of relationships that condition social norms and understandings that instantiate oppression. Oppression leads to problems for Miller's call for care to alleviate harms to agency as there is often little than can be done by a single individual — either the agent in question or by a care provider attempting to help another agent with pursing her self-determined ends - in order disrupt the restrictions imposed by oppression. Oppression places systemic and pervasive limits on the ways oppressed persons can express their agency. There is no singular directed response, such as those implicated in Miller's duty to care, that can combat the effects of oppression on agents. The full discussion of this issue will take place in Chapters 3 and 4.

For now, I will employ the discussion of the relational nature of agents to develop definitions of the skills of relationality and emotionality. Since agents are themselves relational, they will require the skills of relationality, emotionality, and rationality to express their agency within their varied relationships. I will also argue that these abilities are wholly interconnected. It has already been shown that, according to Miller, relationality and emotionality are going to be at times connected. However, one of the problems in Sen's account was his focus on a constrained account of rationality. I argue that relationality, emotionality, and rationality are wholly interconnected and together 
contribute to the enhanced effectiveness of agency. The thoroughly relational nature of agents allows me to anchor rationality, relationality, and emotionality within an account of agency without having it tied to Miller's individualistic duty to care. The process of determining good reasons, rationality as Sen construes it, will rely on the skills of relationality and emotionality in a way that both Sen and Miller do not fully acknowledge.

\section{Defining Relationality}

The set of skills required to maintain and navigate relationships well are what comprise the ability of relationality. One must be able to communicate with others effectively and learn to balance her own needs with the demands of others. Exercising relationality as an ability requires being personable; one needs to be approachable and open to socializing with others in order to both initiate new relationships and maintain existing ones. There is also a need to be sensitive to the particularities of a specific person with whom one is in a relationship. This requires being able to really listen to others and identify what is important to them. This is similar to the call for attentiveness within Miller's duty to care. There must be recognition that others differ in their unique perspectives on the world and they may react in ways that are unexpected. The effective agent, skilled in relationality, can handle all of the challenges one faces in relationships and can maintain relationships despite these challenges. Agents may attempt to deepen their personal relationships with others as part of reaching their personal goals and valued ends. To deepen a relationship, one must be sensitive to the needs of others. She must be able to identify what others need from her, be able to offer that to the other person, and make reasonable demands of that other person. It is likely that agents will want to have stable, satisfying, and 
personally valuable relationships with others; or at least work towards getting their relationships to such a level on a continuous basis. To do all these things effectively calls for relational skills and practices for developing those skills.

Those we are in relationships with have the power to affect our ability to act as an effective agent through the presence of or lack of support. In good relationships, others help us to achieve our own personal agential goals. They can offer their assistance and take steps to further our goals alongside their own whenever they are able to do so. However, sometimes those we are in relationships with can limit our expression of agency. They could discourage us from pursuing our goals and values through plainly stopping us from doing so. The barrier to expressing agency could also be more insidious. Those we are in relationship with may treat us without respect and lead us to believe that our own perspectives are not valuable. It is then relevant to the skill of relationality to foster the development of good relationships. These relationships contribute to the strengthening of one's expression of agency instead of inhibiting it. A relationship that does not support the individual's agency would then be a bad one, one that the individual should be aided by others in leaving, ending, or even saving it so that the members of that relationship support one another instead of holding each other back.

The relevance of relationality to agency is twofold. Not only are certain social skills required for the reaching of agential goals, but certain kinds of relationships are better suited than others to facilitating effective agency. Both of these concerns must be addressed when looking to effectively expand the agency of those who are limited in their capacity to realize their varied goals and values. Since the self is embedded in relationships with other people, the skill of relationality will be indispensible to agents 
for expressing their agency in ways that do not cause serious problems within their enduring set of relationships.

While I have thus far discussed relationality in more particularist terms, as in specifying the role of this skill in personal relationships, the broader network of relationships will also affect the skill of relationality. Broad social norms and values will condition the resources different agents within a particular relationship are presumed to deserve. ${ }^{129}$ For example, broad social understandings of 'women' and 'men' will drastically affect the relationships between particular women and men. This will in turn affect the skill of relationality because broad social understandings will determine the appropriate ways of participating within relationships between a man and a woman. It will affect, for instance, what a woman can reasonably demand from a man, the expectations she can have of him, and what she owes him (and vice versa) within those relationships. If a woman is interested in maintaining her relationship with a man, she may need to (or believe that she must) cater her demands of him in terms of broad social understandings.

The broad network of relationships, insofar as it conditions particular relationships, will inform relationality. This is one of the major problems with Miller's push to consider only the individual level. There really is no distinct individual level to consider. Everything at that level is heavily affected by the relationships beyond the particular individual. This is especially troubling when the broad network of relationships is characterized by oppressive norms, ones that will flow through the network to affect what counts as the skill of relationality in ways that limit or harm agents. I will explicitly

${ }^{129}$ Koggel, "Relational Approach to Equality," 72 
explain how this is so constraining to agents in the next chapter. What is important to note for now is that broader norms affect expressions of agency in part through its impact on relationality.

\section{Defining Emotionality}

Our emotionality is our ability to feel emotions and respond affectively to the world around us. Emotionality can be developed through the improvement of our own emotional responses as well as our ability to identify what others are feeling. When it comes to maintaining a personal relationship, the agent must be able to thoroughly understand what the other is feeling and why. In many cases, the presence of certain emotions is required for the maintenance of a relationship. Due to the relevance of emotions in terms of our connection to other people, it is unsurprising that relationality and emotionality are often intertwined and that both are also needed to inform rational decision making processes. For instance, the criteria for the goodness of a particular relationship can depend on the expression of the appropriate level of the right kinds of emotions by the parties within that relationship. If one member of a personal relationship is uninvested emotionally, we tend to say they are not doing an acceptable job interacting well within that relationship. In terms of a parent-child relationship, if a parent fails to adequately provide the acceptable type and amount of love to her child then she is considered a bad parent. This failure is a result of the inability to be appropriately emotional toward the child. Relationships will usually require a correct measure of appropriate emotionality.

I will not delve into specifics concerning what emotions count as appropriate or positive and which do not. Virtue ethics can offer insights here through the Aristotelian 
understanding that there are appropriate emotional reactions and ways of improving the appropriateness of one's emotional reactions. ${ }^{130}$ What is important for my purposes is that there will be broadly accepted norms concerning what emotions are considered appropriate for agents within a broad network of relationships. Just as the broad network of relationships informs relationality, it will also inform emotionality. There will be broad understandings concerning what it is appropriate for people to feel in response to certain things. Broader understandings will then inform particular agents about how they should work to control their emotionality to ensure they are expressing their emotions appropriately. However, when broad social understandings are overly limiting, agents will be restricted from expressing their emotions honestly due to limiting social assumptions concerning what it is appropriate for them to be feeling. In particular, oppression often leads to the dismissal of the emotions of certain oppressed groups through the broad social understanding that their experience of oppression is normal, acceptable, and not the sort of thing they should be responding to emotionally. Attending to the emotions of oppressed groups, such as their anger, may reveal insights into how broader norms shape relationships in ways that structure what is taken to be reasonable and rational.

The broad network of relationships will also dictate whether or not experiences of emotional duress are normal and acceptable. Agents will be informed by broad social structures of what weight to give their emotionality; specifically how relevant it is as a guide for one's expression of agency. In structures of oppression, the emotions of oppressed persons tend to be systematically dismissed as less pressing or deserving of

\footnotetext{
${ }^{130}$ See Aristotle, Ethics III 7.1115b11-20 and Martha C. Nussbaum, The Therapy of Desire: Theory and Practice in Hellenistic Ethics (Princeton: Princeton University Press, 1994), 78-101.
} 
respect than the emotions of those who are more privileged. Sue Campbell argues that certain emotions will be categorized in ways that allow others to dismiss the perspectives of those experiencing those emotions and this dismissal delegitimizes these experiences. ${ }^{131}$ This further demonstrates some of the possible negative effects of oppression on agents' skills of emotionality and the way in which the broad network of relationships will inform agents concerning which emotions are appropriate and which are not. The line between emotions and reason is further blurred because social structures can dictate what it is rational for certain agents to feel and express.

\section{The Inextricable Interconnection of Relationality, Emotionality, and Rationality}

Most activities will be complex enough that one cannot be a most effective agent without drawing on multiple abilities at once. Miller leaves it open to agents to determine for themselves which abilities they will draw on to achieve their specific goals and values. ${ }^{132}$ However, I think there will be many cases where the effective expression of agency will require an appreciation of the interconnections between these abilities. Relationality, emotionality, and rationality will often overlap in ways that make it impossible to draw on one without consulting one or both of the others. This is important to note especially because helping others to develop their agency will require an appreciation of the complex relationship between the abilities that make it possible. Helping someone to be more rational may require advancing their relational and emotional abilities. The same could be said for any of the abilities. The interconnection then must be recognized to help agents to be most effective and in control of their own lives. Otherwise, in attempting to

\footnotetext{
${ }^{131}$ Sue Campbell, "Being Dismissed: The Politics of Emotional Expression,” Hypatia 9.3 (1994): 46-55.

132 Miller, Ethics of Need, 76.
} 
separate these abilities, agents will be incredibly limited in their ability to navigate their thoroughly relational world effectively and according to their own values.

In Chapter $1 \mathrm{I}$ argued that Sen fails to recognize that rationality is itself constituted through our relationships with others due to our fundamental need for others to help us to develop our own capacities; especially early on in our lives. Without relationships with others who have well-developed skills of relationality and emotionality, people could not gain the capacity for rationality. If our parents were exclusively focused on self-interested goals or solely on the development of our rational capacities, our agency could never have been. Agents require parents, guardians, and others early in their lives with developed relational, emotional, and rational capacities for the establishment of their agency in the first place.

If one was to employ Sen's conception of rationality more generally, in terms of reasons that can stand up to critical scrutiny and careful reflection, it would also appear that rationality must be connected with the abilities of relationality and emotionality. I argue that what count as good reasons will come from the abilities of relationality and emotionality and these are in turn conditioned by broad social understandings. There will be times when it is impossible to act in ways that stand up to critical scrutiny, or determine which reasons would actually stand up to such scrutiny, without having extensive emotional and relational abilities. The determination of what action, choice, or value is most reasonable can require knowledge of others, their specific needs, perspectives, and an attunement to their emotions. Because of the fact of relationality, agents are constantly participating in relationships with other people. Due to the omnipresence of relationships, expressions of agency will consistently occur through 
relationships with others making relationality indispensible and always implicated in the determination of good reasons. The skill of relationality is tied up in and with rationality and emotionality. Knowledge of others, relationships, and emotional attunement will be necessary for reflection, the determination of life plans, and the effective judgement of how an agent should act in a given situation. Rationality must consider the input from relationality and emotionality.

The broad network of relationships in which one is embedded will structure the faculty of rationality just as it affects the skills of relationality and emotionality. Broad social understandings will shape particular understandings of reasonableness and determine what frameworks should be used to sort through those reasons that are acceptable and those that ought to be dismissed. What is perceived as most rational then is itself contingent on the relational structuring of a society. Social practices will determine which reasons are actually good reasons as well as which values and preferences are backed by the socially determined 'good' reasons. In the face of oppression, particular agents may be considered unworthy of certain values and thereby it would be socially determined as irrational for them to maintain such values. This comes out of the fact that systems of oppression deem the experience of oppression by certain social groups as completely normal. It would then be deemed irrational within a system of oppression for members of oppressed groups to view such treatment as unjust. Instead, the oppression is characterized as normal and thereby the effects it has are also presumed to be normal. In this system, it is unreasonable to value an end to oppression because people are made to believe that it is impossible for society to be arranged in any other way. The assumption is that the effects of oppression cannot be changed because those 
are simply the way that things are. It is inherent to oppression that the negative effects it causes tend to be dismissed and the perspectives of oppressed agents tend to be treated as irrational.

\section{The Complexity of Expressing Agency: The Divided Interests of Agents}

A crucial aspect of the relational account of the self is that the self is not a single unified entity. Certain traits, values, and preferences will be more pronounced in certain contexts than in others. We may behave in a certain sort of way in one set of relationships and in a completely different sort of way in others. As Serene J. Khader argues, the concepts with which we identify can be "multiple and contradictory" and can be "comprised of varied...elements." ${ }^{, 133}$ It is possible that one holds many values that potentially bring forth contradictions in action. It may not always be obvious that one available choice coheres best with all of an agent's values. This puts an added strain on conceiving of agency solely in terms of rationality. There is often going to be a lot at stake for the agent when making a choice. Rationality, construed as distinct from relationality and emotionality, will not provide the insight required for the agent to choose most effectively, in a way that fits best with her values or with what is possible within her varied relationships. Once again, the thoroughly relational nature of selves and their contexts makes many facts beyond rationality alone incredibly salient to the agent for the effective expression of her agency. It is up to the agent to find a way to balance her varied concerns based on what she really wants or needs to be doing; subject to the conditions imposed by the broad network of relationships in which she is situated.

${ }^{133}$ Khader, Adaptive Preferences, 117. 
The priorities and values an agent determines as most relevant may continuously change depending on the particular relationship they are considering. The agent will engage her diverse relational, emotional, and rational skills to determine how it is she is permitted to act within certain relationships that best coheres with the values she has chosen to prioritize. For instance, an agent may choose to accept harms within a relationship with a romantic partner but refuse to accept them in the workplace. This is because the effect of broad social understandings may be felt more strongly in certain types of relationships between specific types of agents than in others. Khader highlights this effect in terms of self-entitlement. She claims "people experience themselves as more or less worthy depending on whom they are interacting with and whom they are comparing themselves to." ${ }^{, 134}$ Perhaps a single person sees themselves as less deserving than certain others but not all others. So, an agent may feel she does not deserve to face harm in some of her relationships but that this is an acceptable cost in other relationships. This could be affected by her priorities toward maintaining some relationships over others. An agent's skills are informed by her context and they will help her to navigate her relationships in ways that best express her agency.

The self is not best conceived as unified. When one aspect of our lives imposes negative consequences, it is possible for the effects to be felt within one domain instead of across all aspects of our lives and selves. This provides the chance for an agent to act in ways that cohere with her values in some contexts even if other relationships impose limits on the realization of that agent's broader goals and values. The multiple and contradictory aspects of agents' selves allow them to diversify their expressions of

${ }^{134}$ Ibid. 
agency depending on the immediately relevant context in which they are attempting to express their agency. Relationality, emotionality, and rationality together provide the agent with access to finding ways to effectively express her agency within relationships. They allow her to determine the ways of getting the most from her relationships - even in relationships that impose limits on her.

For instance, imagine a relationship between a husband and wife in a hyperpatriarchical society. There is an understanding within this society that there are very specific things a wife owes her husband within this type of relationship. She owes him subservience; her desires must be overridden by his own in all cases. This informs the wife's relationality insofar as she believes certain behaviours are necessary within this context to maintain the relationship. If she does not subsume her needs to his, she will face violence or an end to the relationship. This may not be an option for her. She may value her marriage and desire that it continue. She may surmise, through the use of her skills of emotionality and relationality, that her husband is willing to negotiate with her about certain things. She senses his irritation when objecting to his demands for sexual intercourse but notes he is untroubled when she makes demands for more resources to ensure her children's health. She learns to navigate this relationship with her husband and determine what he will allow her to demand of him through the use of her agential skills. Relationality, emotionality, and rationality supply her with the information needed to help work through how to get as much as possible from this relationship that she has reasons to maintain within a broader social context.

Nonetheless, she may behave entirely differently in a different relationship. For example, in a relationship with a female friend she may feel she is more of an equal. 
Through the skills of relationality, emotionality, and rationality, she surmises that she does not need to censor her thoughts or opinions with that friend because she has noticed that there is not the same hostility she has experienced with her husband towards any of her personal values and goals. The fact that she feels as if she is not an equal in her relationship with her husband is a result of the broad social conditions. These different behaviours seem to contradict one another despite being those of a single agent. People will behave differently in different contexts because the change in context may signal a change in the relevant actions and behaviours expected of that agent. One can act like a completely different person depending on the immediately relevant relationships in which she is participating that condition the way she relates to different people based on her affiliations with certain social groups. ${ }^{135}$ Agents will require the skills of relationality, emotionality, and rationality together to navigate the many different relationships in which they participate and, thereby, find ways to most effectively express their agency. I will show, however, that there is more to unpack and analyze with respect to the broad network of relationships in which agents are shaped by oppression.

\section{Conclusion: The Need for an Account of the Broad Network of Relationships}

An agent will require the abilities of rationality, relationality, and emotionality taken together to most effectively navigate her relational context. In many cases, broad social understandings will impose restrictions on the activities individuals believe are available to them. This could be both in institutionally realized ways - as in formal barriers to the activities of individuals based on social beliefs — or in more insidious ways. In the next chapter, I will explore the insidious effects of oppression as it puts pressure on agents in

135 Khader, Adaptive Preferences, 118. 
broad networks of relationships. Oppressed agents will face social pressures and restrictions that affect their agency in certain ways. Members of oppressed groups are also restricted from behaving counter to social norms due to the potential harms oppressed individuals can face when trying to disrupt such norms. ${ }^{136}$

Broad social conditions set the stage for the sorts of choices and avenues available to agents. Ideally, we would want no limits imposed by such social conditions; however, we do not live in an ideal world. All societies are characterized by social conditions that impose at least some limits on some agents. In fact, some societies impose strict limits on agents' expressions of agency. I will go on to discuss the broad social conditions, oppression, and the need for a relational account of autonomy in the chapter that follows.

${ }^{136}$ Sherwin, "Relational Autonomy and Global Threats", 17. 


\title{
Chapter 3
}

\section{Oppression and Autonomy: Supplementing an Account of Agency}

\author{
$\underline{\text { Introduction }}$
}

Sen and Miller both attempt to address agency without fully considering the broad network of relationships within which all agents are embedded. Agents cannot be considered in abstraction from their contexts because broad networks of relationships determine the norms, values, and understandings that go on to structure the relationships within which agents participate. I argue that pairing an expanded account of agency with a relational account of autonomy can make it possible to deal with the added constraints on agents that exist at the broader social level. I distinguish agency and autonomy; the person who exhibits agency and yet makes choices that do not, overall, appear to be good for her lacks autonomy due to constraints imposed on her by her social conditions.

One of the major concerns I have expressed throughout the chapters so far has been the impact of oppression on agents. In this chapter, I will outline Iris Marion Young's account of oppression. The presence of oppression within society leads to a variety of limits placed on agents that many agents will be unable to challenge on their own. I use Young's account of oppression because it demonstrates the complex, multifaceted, and relational nature of oppression. Oppressed persons necessarily experience constraints on the control they have over their own lives due to the very nature of oppression. After a detailed discussion of oppression, I will connect Young's account to the problems I identified with Miller's and Sen's accounts of agency in terms of broad social conditions. I will argue that there is a need to go beyond examining specific agents 
in order to account for these broader social conditions and their effects. An individualistic approach cannot account for the impact of oppressive social conditions.

I will draw on Susan Sherwin's and Catriona Mackenzie's accounts of relational autonomy. Their accounts provide an explanation for expressions of agency oppressed agents exhibit that appear to run counter to those agents' broader goals and values. A relational account of autonomy offers realistic solutions to the cases where agents are constrained by their social conditions in ways they are powerless to change. Solutions must come at the broader level in order to change conditions that are not conducive to autonomy and are therefore imposing limits to agents in ways agents cannot combat on their own. I will explore possibilities for solutions that will impact this broader level in the following chapter.

When social conditions generate any of the faces of oppression identified by Young, those social conditions are not conducive to full autonomy for all agents. However, it remains possible for agents within such conditions to effectively express their agency even in the face of constraints on their autonomy. Oppressed agents will need help from others to restructure conditions such that they are not oppressive and therefore are fully conducive to autonomy. Agents can, nevertheless, be aided in being more effective agents through the development of their relational, emotional, and rational skills. I will briefly describe the distinction I wish to make between agency and autonomy first.

\section{The Distinction between Agency and Autonomy}

There are two levels at which individuals can be constrained from acting in the world and on their own terms. 'On their own terms' refers to acting in ways that cohere with 
people's goals and values, or in terms of the goals and values they choose to prioritize in a given case. Constraints on action arise at the level of the specific individual as well as at a broader level. At the level of particular agents, there will be times when people require help from others to establish, maintain, and restore their agency. As Miller explains in her duty to care, this response will have to be particularized to the specific needs of the agent in question. Also, agents will require the advancement of their relational, emotional, and rational skills to help them act as most effective agents. However, the broader level—as in the wide web of relationships that structure one's social world, structures the norms, values, and understandings of a society—will inevitably affect all the agents living within that society insofar as such norms will delineate what is normal and acceptable for people to value being and doing within that society.

I argue that 'agency' in a full relational sense is associated with individual values and choices while 'autonomy' is associated with broad social conditions under which agents live their lives and interact with others throughout their lives. Insofar as each is implicated in a different realm of relationships, each calls for a different type of response. Since the solutions to inhibited agency are different from that of inhibited autonomy, the distinction plays an important role when looking to help expand agency. Without this distinction, the expansion of agency will always be held up at the point where agents meet all the criteria to be considered agents and yet continue to make choices that seem to work against some of their values. Oppressive social conditions can affect what agents can do in ways that cause them to make choices that, while in their best interest in one sense, still succeed in maintaining oppressive social conditions. 
Sherwin distinguishes agency and autonomy and then goes on to argue for the need for an account of autonomy "to make sense of the puzzling fact that people frequently choose options that are, in some sense, contrary to their overall well-being."137 Sherwin is trying to single out the sorts of cases where our intuitions would lead us to believe that the agent in question could not possibly be acting in a way that represents their values due to the long term negative effects of the decision she is making. These long term effects include continued oppression for the agent and for the social group to which she belongs. While 'contrary to their overall well-being' may not be the best criterion, it is at least one of the cases where it seems as if something may be amiss. This is because it seems strange that someone who is truly free would choose to do something that is not good for them more generally.

However, Sherwin explains that oppression causes these inexplicable sorts of behaviours in which someone appears to be making a choice (they are not obviously forced to do something) although, that choice appears overall to be bad for that person. As she explains:

This phenomenon of actively supporting activities that reinforce one's own oppression is a hallmark of being oppressed in that it reflects the classic double bind where, no matter which option one chooses, there are negative consequences for the agent. When in a double bind, a person can certainly display agency — she can make an informed and rational choice — but it does not seem right to call her choice autonomous when the structure does not offer her any option that fully reflects her deepest values and interests. ${ }^{138}$

Although, I disagree with the way Sherwin has characterized agency —as there is much more to agency than making an informed and rational choice- she makes an important point about the effects of oppression on the choices that are available to agents in the first

${ }^{137}$ Sherwin, "Relational Autonomy and Global Threats", 17.

138 Ibid. 
place. Moreover, she points out that in the face of oppression, it will often be best for an agent to act in accordance with the system of oppression due to the potential harms one may suffer if one attempts to challenge those oppressive norms. ${ }^{139}$ Choices that perpetuate oppressive norms are not autonomous but can be effective expressions of agency under conditions of oppression. People can secure self-determined ends through the use of relationality, emotionality, and rationality, although the set of possible ends they perceive as open to them and the actual avenues open to them to achieve those ends may be constrained. The important insight to take from Sherwin is that choices can be effective expressions of one's agency even when agents are not fully autonomous. Oppressive background conditions are pervasive and, while they affect expressions of agency, they do not necessarily make agency impossible.

\section{Young's Account of Oppression}

Young argues that oppression is often generated through social structures and afflicts various social groups. I will briefly explain these two aspects of Young's account before moving on to what she identifies as the "faces of oppression". These are exploitation, marginalization, powerlessness, cultural imperialism, and violence. It will be clear that oppression occurs in ways that the oppressed are often unable to change because oppression is structured specifically in ways that pressure oppressed persons to accept it as normal. The impact of oppression on agents must be recognized both within an account of agency as well as beyond it, in terms of an added account of autonomy.

\footnotetext{
139 Sherwin, "Relational Autonomy and Global Threats", 19.
} 


\section{Oppression as a Structural Concept}

Young's account of oppression begins with the assertion that oppression is often structural. It is not simply a result of the tyranny of powerful individuals limiting what certain people are able to do. ${ }^{140}$ Oppression can refer to "systemic constraints on groups" that "are embedded in unquestioned norms, habits, and symbols, in the assumptions underlying institutional rules and the collective consequences of following those rules." ${ }^{141}$ It is not always obvious that oppression is happening because it can be a result of deeply entrenched social norms. This means that entire social structures can be oppressive to certain groups and may be presumed to be normal despite the distinct problems such constraints cause for oppressed groups. It also means that oppression is rooted in many different places and that in order to end oppression, a dynamic and multipronged set of solutions that combats varied and deep structural norms will be required.

\section{$\underline{\text { Social Groups }}$}

Young explains that "oppression refers to structural phenomena that immobilize or diminish a group."142 She also explains that a 'group' is a social category that comes about via the differentiation of people through social interaction. A social group is a collective of people that are differentiated from others due to some perceived similarity between members within that group and a perceived difference from those who are outside the group. ${ }^{143}$ I use the term 'perceived' because there will be cases where the group delineation occurs because people understand there to be some shared or distinct

\footnotetext{
140 Young, Politics of Difference, 40.

${ }^{141}$ Young, Politics of Difference, 41.

142 Young, Politics of Difference, 42.

143 Young, Politics of Difference, 43.
} 
trait even if that is not actually the case. Social groups are important because they have "specific consequences for how people understand one another and themselves." ${ }^{144}$ One is not always able to decide for herself whether or not she is a member of or excluded from certain social groups. ${ }^{145}$ Often, that is a decision made by individuals who already exhibit greater social power; possibly due to their membership in a social group that is privileged insofar as members, solely in virtue of their membership, are granted greater social and political power.

Just as I discussed in Chapter 2, Young claims that social groups will "constitute individuals" as "a person's particular sense of history, affinity, and separateness, even the person's mode of reasoning, evaluating, and expressing feeling are constituted partly by her or his group affinities."146 This informs the broad network of relationships that then informs the agents within them. Considering the fundamentally relational nature of selves, their varied socially determined group membership will seriously impact agents, their skills of relationality, emotionality, and rationality, and their values. Despite the potential unchoseness of one's group membership, an agent will inevitably be shaped by the social perceptions attached to the groups she is sorted into. Perceived group membership will also often affect the way others treat an individual as "some people mistakenly believe that group identification makes a difference to the capacities, temperament, or virtues of group members." ${ }^{147}$ Social groups play an important role in the formation of particular agents' relational, emotional, and rational skills insofar as

\footnotetext{
144 Ibid.

${ }^{145}$ Young, Politics of Difference, 46.

${ }^{146}$ Young, Politics of Difference, 45.

${ }^{147}$ Young, Politics of Difference, 46.
} 
group memberships delineate much of the content of those skills for specific agents in each different social group.

It is through the grouping of agents into various social groups that the broad network of relationships works to impose oppression on the particular agents who are perceived to be members of oppressed social groups. Their membership in these groups impacts the ways in which agents make choices or perceive themselves. Insofar as they identify with their social group membership, they will be informed by the traits associated with that group. Any agent could be member to multiple different social groups that each affects agents' self-perceptions and agential skills in different and potentially conflicting ways. This relates back to my discussion concerning the divided interests of agents which, due to the relational nature of the conditions under which agents exist, can be multiple and contradictory. ${ }^{148}$ Oppression can complicate expressions of agency for oppressed agents as different social groups impose different constraints.

Once one accepts that the source and operation of oppression is structural, and that there exist social groups that can affect people both in terms of their own development and what others assume they are capable of or deserve, the next step in Young's account is to explain what she terms the five faces of oppression. Young claims "oppression is a condition of groups" and that the five faces cover all the ways a group can experience oppression. ${ }^{149}$ There is no single comprehensive and generalizeable account of oppression that can adequately cover all instantiations of oppression. ${ }^{150}$ It is for this reason that Young's account includes multiple faces of oppression as this

\footnotetext{
148 Khader, Adaptive Preferences, 117.

${ }^{149}$ Young, Politics of Difference, 40 and 42.

${ }^{150}$ Young, Politics of Difference, 42.
} 
addresses all the different ways oppression can manifest and affect members of different social groups within societies. While some groups may experience one or two of these, it is also possible to experience them all in some form. Additionally, particular agents may be affiliated with numerous social groups causing complications, overlaps, and contradictions in their experience of oppression. Oppression is complex and leads to limiting conditions that are imposed on people through no choice of their own. The strength of Young's account is its sensitivity to the variety of ways oppression occurs. Whether agents only encounter one of the faces or all five of them, those agents are subjects of oppression. ${ }^{151}$

\section{Exploitation}

Young's first face of oppression is exploitation. She claims that "this oppression occurs through a steady process of the transfer of the results of the labor of one social group to benefit another." ${ }^{, 152}$ Recall that membership in a particular social group could be arbitrary. This means that it is possible that through the chance of birth and the perceived possession of certain group-specific qualities, you could end up in a group that systematically benefits another, also arbitrarily delineated, social group. The benefit would be accrued by the privileged directly through the disadvantage experienced by the oppressed. The disadvantage would persist and continually worsen, compounding the exploitation as time goes on. ${ }^{153}$ For instance, a disadvantaged group can continue to fill positions that are dangerous and low paying so that advantaged groups do not need to put their lives at risk and are able to make a profit off the low wages paid out to the members

${ }^{151}$ Young, Politics of Difference, 64.

152 Young, Politics of Difference, 49.

153 Ibid. 
of the disadvantaged group. If this continues for a long period of time, the less fortunate group continues to occupy that lower space because they are never able to profit enough to end the cycle. Meanwhile, the advantaged group continues to get further and further ahead due to the benefits accrued at the cost of the disadvantaged group. In this case, the disadvantaged group faces exploitation and is therefore oppressed. This problem also cannot be remedied purely through redistribution of goods because exploitation occurs and persists through broad social structures; therefore, these structures must be altered to make the changes necessary to end exploitation. ${ }^{154}$

Exploitation may occur in terms of gains that are not strictly income. There are many forms of labour that certain groups engage in that benefit other groups that do not include any exchange of money. Young uses the example of women who, often, through their designation as 'women', are expected to engage in activities that systematically benefit those belonging to another social group: 'men'. She explains that "women undergo specific forms of gender exploitation in which their energies and power are expended, often unnoticed or unacknowledged, usually to benefit men by releasing them for more important and creative work, enhancing their status or the environment around them, or providing them with sexual or emotional service." ${ }^{155}$ Exploitation often occurs such that the advantaged do not acknowledge the benefits. Yet, it significantly disadvantages the exploited by limiting them in terms of what they are able to spend their time doing and what sort of "work" they are supposed to be doing. There are assumptions, tied to their social group membership, concerning the appropriateness of what turns out to be exploitation.

\footnotetext{
154 Young, Politics of Difference, 53.

${ }^{155}$ Young, Politics of Difference, 51.
} 
Agents are then constrained in terms of the work they reasonably have access to and the expectation others will have of them in terms of the work it is assumed they should be doing. However, as a symptom of oppression more generally, most people will not openly admit or recognize that exploitation is taking place. This is because norms that result in exploitation can shape the values particular agents possess and the expectations other people have of the exploited agents. For instance, women may always be expected to put in more labour within the home and have therefore decided to find value in engaging in work inside the home. The selection of this value seems to be taking place because it has been socially determined that this is something women should be doing rather than something they would want to be doing regardless of the background social conditions. In different social conditions, exploited persons may never choose to value exploited forms of labour because there is no broad social understanding that this is work they should be doing. It is precisely due to the impact of oppression on the very framework through which agents are deciding how to best express their agency that I defended the need for a second concept, autonomy. Autonomy would cover these sorts of cases of limits on the expression of agency that occur through frameworks that determine which agents should be valuing what sorts of work.

\section{$\underline{\text { Marginalization }}$}

Young contrasts marginalization with exploitation insofar as there will be individuals whom "the system of labor cannot or will not use."156 They are not exploited because they are not permitted to engage in any sort of marketable labour whatsoever. Young calls this one of the most dangerous faces of oppression as "a whole category of people is

${ }^{156}$ Young, Politics of Difference, 53. 
expelled from useful participation in social life and thus potentially subjected to severe material deprivation and even extermination." ${ }^{157}$ A social group's marginalization can cause such severe material deprivation that individuals do not have enough to survive. They are forced out of the system of labour such that they are unable to provide for their own basic material needs. While some argue that this can be dealt with through the provision of material needs, the marginalized can continue to experience oppression "in the form of uselessness, boredom, and lack of self-respect." ${ }^{\text {5158 }}$ This would occur due to the fact that "most of our society's productive and recognized activities take place in contexts of organized social cooperation, and social structures" which would make "processes that close persons out of participation in such social cooperation are unjust." ${ }^{159}$ They are unjust specifically because they make it impossible for marginalized persons to engage in activities that would provide their lives with meaning.

Some of the groups that notoriously experience the face of marginalization are the elderly, the homeless, those with mental illnesses, and those with disabilities. ${ }^{160}$ These are all groups of people who are systemically left out of the typical patterns of organized social cooperation that give life meaning for those who do not face this form of oppression. As Young explains, "being a dependent in our society implies being legitimately subject to the often arbitrary and invasive authority of social service providers and other public and private administrators, who enforce rules with which the marginal must comply, and otherwise exercise power over the conditions of their

\footnotetext{
157 Ibid.

${ }^{158}$ Young, Politics of Difference, 55.

159 Ibid.

${ }^{160}$ Young, Politics of Difference, 54.
} 
lives." ${ }^{161}$ It is clear that agents who are members of marginalized groups will face serious limits to the ways in which they can express their agency. Institutions within society will explicitly restrict marginalized agents from participating in activities that many find meaningful. Also, marginalized people will be cut off from forming and maintaining relationships with those who are not marginalized because they are restricted from accessing the spheres in which those relationships take place. Further, marginalized agents will likely experience greater fundamental need as they are cut off from securing basic necessities for themselves. Marginalized agents cannot change these oppressive structures because their oppression is organized in such a way that they are explicitly left out of them.

\section{Powerlessness}

Young describes the powerless as "those who lack authority or power..., those over whom power is exercised without their exercising it; the powerless are situated so that they must take orders and rarely have the right to give them." ${ }^{\text {162 }}$ One of the examples Young uses to clarify powerlessness is the distinction between professionals and nonprofessionals: nonprofessionals would be the powerless in relation to the professionals who possess power insofar as professionals tend to be granted power or authority over others. ${ }^{163}$ Young explains that "professionals are privileged in relation to nonprofessionals, by virtue of their position in the division of labor and the status it

\footnotetext{
161 Ibid.

162 Young, Politics of Difference, 56.

${ }^{163}$ Ibid.
} 
carries" and that "the powerless lack the authority, status, and sense of self that professionals tend to have." 164

However, powerlessness also occurs outside the relation between professionals and nonprofessionals. Many will experience feelings of powerlessness in the realm of other relations where they similarly lack authority insofar as others presume they have none. There are many who experience the injustices Young identifies with powerlessness: “inhibition in the development of one's capacities, lack of decisionmaking power in one's working life, and exposure to disrespectful treatment because of the status one occupies" are examples of injustices suffered by the powerless. ${ }^{165}$ All of these things can take place in a variety of realms of human relationship. People may lack decisionmaking power within their families, they may miss out on the development of their capacities early in their lives, and may face disrespectful treatment due to presumptions concerning their lack of authority more generally. Powerlessness is rampant within a broad network of relationships. Powerlessness can easily occur in realms beyond the professional and nonprofessional one.

In terms of agency, there will be agents who are powerless to change or alter the conditions that are limiting their effective expression of agency. The broad social conditions may structure the world such that powerless agents are not permitted authority. This is not just authority in relation to others (which does occur and is still troubling) but also in terms of authority over themselves. For example, many women are not granted full authority over their own bodies. There are restrictions placed on them legislatively: for example many claim abortion should not be within the realm of options

\footnotetext{
${ }^{164}$ Young, Politics of Difference, 56 and 57.

165 Young, Politics of Difference, 58.
} 
available to women. Women can be left powerless with respect to the decision of whether or not their bodies must host a fetus.

While this is one more concrete example of the powerlessness women face, the category 'woman' can have powerlessness built into its very definition. Women's thoughts and experiences are dismissed when they are at odds with the thoughts and experiences of men because it is built into the very definitions of 'men' and 'women' that when these conflict, a man's thoughts and experiences are more legitimate than those of women. Women are then defined as deserving less authority than men on all matters. Agents who are slotted into the social group of 'women' will then continuously face powerlessness within their relationships insofar as they are broadly understood to be powerless. Of course, this form of oppression can affect groups other than 'women'. This is just one example of a group that is defined in terms of their perceived powerlessness.

\section{Cultural Imperialism}

Young explains that "to experience cultural imperialism means to experience how the dominant meanings of a society render the particular perspective of one's group invisible at the same time as they stereotype one's group and mark it out as the Other." ${ }^{166}$ There is an assumption that a particular group's culture is the universal experience and anyone who belongs to a culture outside of that is distinct and abnormal. ${ }^{167}$ In this way, one sort of perspective is assumed to be the norm against which others are measured and judged. Then, due to the assumed normalcy of the dominant culture, "the dominant group

\footnotetext{
${ }^{166}$ Young, Politics of Difference, 58-59.

${ }^{167}$ Young, Politics of Difference, 59.
} 
contrasts the differences which some groups exhibit as lack and negation." ${ }^{\text {"168 }}$ The dominant group sets the other groups aside as less than itself.

Grouping by culture informs those outside the group and those inside the group. Those outside make assumptions about the members of that group that can be completely false or mistaken. Meanwhile, those inside the group may have their understandings of themselves shaped by their forced group categorization. Due to one's membership in a certain group, one may come to believe that she actually fits or should work to fit the criteria associated with that group. Group membership can alter the way someone sees herself in potentially harmful ways. Young explains "that the oppressed group's own experience and interpretation of social life finds little expression that touches the dominant culture, while that same culture imposes on the oppressed group its experience and interpretation of social life." ${ }^{169}$ It is in this way that members of certain cultural groups can be systematically disadvantaged and, therefore, oppressed, through cultural imperialism.

As an example, Young explains that:

These stereotypes so permeate the society that they are not noticed as contestable. Just as everyone knows that the earth goes around the sun, everyone knows that gay people are promiscuous, that Indians are alcoholics, and that women are good with children. White males, on the other hand, insofar as they escape group marking, can be individuals. ${ }^{170}$

There is a type of powerlessness faced by agents who do not participate in what is presumed to be the dominant culture of 'white' and 'male', insofar as they cannot change these stereotypes because they are treated as facts rather than as the social fabrications

168 Ibid.

${ }^{169}$ Young, Politics of Difference, 60.

${ }^{170}$ Young, Politics of Difference, 59. 
that they are. Faces of oppression are constantly overlapping as agents navigate their social contexts. Cultural imperialism will impose meanings and values on agents who are relegated to the non-dominant social groups. This will inevitably affect the ways these agents choose to express themselves as they will come to identify themselves with the traits associated with these social groups even when those traits do not genuinely represent the members of those social groups. Agents will face pressure to uphold traits that may contribute to their oppression in ways that, through the very nature of oppression, they will be unable to fight against. These meanings will be broadly accepted, and members of non-dominant cultures will systematically be cast aside, put down, or forced to identify in a way the dominant culture deems appropriate. Once again, agents will face restrictions on the possibilities for their effective expression of agency.

\section{$\underline{\text { Violence }}$}

The last face of oppression Young identifies is violence. She explains that "members of some groups live with the knowledge that they must fear random, unprovoked attacks on their persons or property, which have no motive but to damage, humiliate, or destroy the person." ${ }^{171}$ There is the continuous threat of harm to one's person simply because of her membership in a group that she was powerless to choose or define. Young claims that "the oppression of violence consists not only in direct victimization, but in the daily knowledge shared by all members of oppressed groups that they are liable to violation, solely on account of their group identity." ${ }^{172}$ This face of oppression encompasses not

\footnotetext{
${ }^{171}$ Young, Politics of Difference, 61.

172 Young, Politics of Difference, 62.
} 
only the experience of violence by certain members of the oppressed social group but also the possible threat to all members of that group.

Those in oppressed groups who experience the face of violence will constantly be in fear of suffering harm. Those who perpetrate this harm or threat of harm will often not face serious punishment due to the perceived normalcy of that violence. Young explains that "even when they are caught, those who perpetrate acts of group-directed violence or harassment often receive light or no punishment. To that extent society renders their acts acceptable." ${ }^{173}$ It is a fact that becomes normalized; people of a certain group will face violence and it is assumed that this is a normal occurrence that will continue. It becomes an accepted social practice that is time and time again tolerated. It is in this way that groups can come to experience systemic violence. The violence is allowed to continue, without recourse. The endorsement of violence against certain groups can come about in a variety of mediums. Plotlines in television shows and movies, jokes, and advertisements can all contain instances where violence against certain groups is condoned and accepted. These add to the normalization of violence for oppressed groups as, everywhere an agent looks, such violence is shown to be completely ordinary and perhaps even justified.

The face of violence will often overlap with other faces: those who are members of social groups who are subject to exploitation, marginalization, powerlessness, or cultural imperialism may also face threats of violence due to their participation in those social groups or in attempting to challenge assumptions concerning their membership to such groups. Two social groups that notoriously face violence are women and black

173 Ibid. 
persons through systemic violence and threats of violence to their bodily integrity. Police brutality inflicted on black persons is presumed to be normal and therefore a situation that does not require attention or work to change. The effects of rape culture on women are also presumed to simply be a reality and therefore defy scrutiny and cannot be changed. Yet, violence and threat of violence seriously limit people from expressing their agency. In order to carry out fairly simple activities, agents are tasked with facing the possibility of serious harm to their person. Black people and women must be wary just walking down the street for fear of facing violence. This will seriously curtail effective expression of agency. The agents facing violence will be unable to do much to stop it and may be violently prevented from expressing their agency.

\section{The Faces in Summary}

It is important to note that there are ways in which each of the faces can reinforce or affect any of the others. It may be the case that the oppressed experience multiple faces at once. In any case, they are each instances of the specific disadvantages and injustices faced by oppressed groups. According to Young, a group that experiences any one of these five faces is being oppressed. ${ }^{174}$ All oppressed persons "suffer some inhibition of their ability to develop and exercise their capacities and express their needs, thoughts, and feelings." ${ }^{175}$ Built into the experience of oppression there are limits placed on persons that they do not deserve to face. An agent cannot maintain a life free from violence or fear if they are slotted into a social group that is subject to systemic violence. An agent cannot participate in society as she wishes if she is marginalized. An agent cannot define

\footnotetext{
${ }^{174}$ Young, Politics of Difference, 41.

${ }^{175}$ Young, Politics of Difference, 40.
} 
herself without being restricted by impositions designated by oppressive norms. There are ways in which each of these faces imposes strict limits on a person's autonomy and thereby on her effective expression of agency. I will argue that the limits placed on agents by oppression take place through the restriction of autonomy within these conditions.

\section{$\underline{\text { Revisiting Problems with Sen and Miller: Oppression and Agency }}$}

I argued in Chapters 1 and 2 that Sen and Miller's accounts of agency do not adequately address the effects of the broad network of relationships in which agents are situated. In particular, they cannot account for the ways oppression will condition and affect agents. A major issue for an account of agency is that oppression, insofar as it is implicated at the level of broad social conditions, cannot be ended by the particular agents facing oppression. Broad social structures affect agents in the following ways: they structure the opportunities made available to agents, affect the goals and values particular agents choose, determine the ways certain agents should be treated, affect the ways agents view themselves, shape the content of relationality, emotionality, and rationality, and what counts as skilled expressions for these abilities. As oppression operates through these broad relationships, exploitation, marginalization, powerlessness, cultural imperialism, and violence can limit agents on all of these fronts. Not only will broad networks of relationships affect agents, but oppression will impose serious limits on agents through many different channels. Since oppression comes out of broad social understandings that tend to be accepted within societies, most will not engage in behaviours that dismantle oppression. The oppressed face serious risks for doing so and are pressured to accept those social understandings. 
Looking back to Sen, I argued that one of the major flaws in his account was the failure to recognize that broad social conditions will have a serious impact on the freedoms available to agents. Miller also failed to recognize that individual agents are subject to overarching social conditions that specifically dictate what it is reasonable for certain agents to value and the choices it is appropriate for them to make. Without an appreciation of the impact of broad social conditions, one could mistakenly believe that the solution for expanding agency always comes at the level of the individual agent. However, when oppressive structures are impacting the agent, one cannot simply address the issue by only looking at how to enhance the agency of that particular individual. Oppression must be addressed at levels beyond the agent, in terms of the oppressive forces in her context. There is nothing the agent can reasonably be expected to do on her own to change the underlying social norms, values, and understandings constraining her avenues of choice.

Recalling the case of women's agency explored in Chapter 1, I argued that providing women the opportunity to access more resources does not erase the broad social conditions limiting their participation in family decision-making or the oppressive conditions within workplaces. The oppression women face in many realms of their lives persists when solutions are restricted to the level of the individual. The agent is being restricted in ways that cannot be alleviated through specific choices made by that particular agent. In conditions of oppression, being categorized as a member of a certain social group will limit what others believe the agent is capable of and even what that agent presumes she is herself capable of. In the face of oppressive social conditions, 
agents are overwhelmingly constrained and are relatively powerless to challenge such conditions on their own.

Sen and Miller both make assumptions concerning the choices made by oppressed agents: those choices are not good for them and those agents should be aided in choosing differently. ${ }^{176}$ For instance, Miller explains that oppressions lead to some strange cases: “(1) cultivation of false fundamental needs that people would not experience were they not in a situation of oppression; (2) suppression of fundamental needs that non-oppressed (or less severely oppressed) individuals normally experience; and (3) a refusal to meet fundamental needs (whether cultivated via oppression or not). ${ }^{1177}$ While it is true that the conditions of oppression may cause choices that appear to be strange, it could be the case that, given the broad structure of relationships in which an agent is embedded, it is the best choice for her to be making. The choice appears strange but is actually the best way for an agent to effectively express her agency given the limits on her activities imposed by features of oppression that she is powerless to control or alter. ${ }^{178}$

Serene J. Khader provides a good example of such a case. She asks us to consider a woman who chooses to prioritize her husband's need for food over her own. She explains, "a woman who undernourishes herself to feed her husband may do so because it helps her feel like a good and respectable woman....She may engage in self-depriving behavior primarily in order to achieve her goal of feeling good about herself, and the higher-order goal of feeling self-worth." ${ }^{179}$ First, it might be the case that within her broad social context the only way to achieve self-worth for a woman is to fit the criteria

\footnotetext{
${ }^{176}$ Sen, Development as Freedom, 190-192 and Miller, Ethics of Need, 132.

177 Miller, Ethics of Need, 38.

${ }^{178}$ Khader, Adaptive Preferences, 83-84.

${ }^{179}$ Khader, Adaptive Preferences, 97.
} 
of the oppressive social definition of a 'good and respectable' woman. In turn, to meet the criteria for this requires sacrificing her needs for her husband's. I agree that the fact that a woman feels like she must choose undernourishment to find self-worth is troubling. However, within the constraints imposed by her context, this may be the best choice available for her. One could argue that it should not be that way, but when conditions of this sort exist there is nothing an agent can do but try her best to navigate those conditions while still expressing her agency as effectively as possible. While the reality that this woman has to choose between her value of feeling self-worth and her, presumably concurrent, value to be well-nourished is not ideal, she may still need to make the choice between these. One of these choices is a better, more effective, expression of her agency according to her own criteria for how it is she would like to act and the values she finds immediately relevant to that choice, even though her understanding of the world, her values, and her avenues of choice are all constrained by overarching oppressive social conditions.

For any given choice, there are likely many complex factors at play. In terms of Khader's example, it could be the case that within the set of options available to her, eating less so her husband can have more is truly the best option for reasons even beyond her value to achieve self-worth. She may rely on her husband for all the resources that contribute to her survival and therefore feel it is best to allow him to be fully nourished since she needs him to be strong and healthy to provide for her more generally. It could also be the case that her relationship with her husband hinges on the fact that she fulfills the role of a 'good and respectable woman' and ending that relationship, due to broader structures of oppression, would cause much greater harm than short term 
undernourishment. Without her husband, she may face destitution; she may have children relying on her and her husband for survival. In this way, she is choosing to be undernourished because it is the option available to her that coheres best with her overall set of values.

I am arguing that, in the face of oppression, an agent can express her agency. An agent can also express her agency more or less effectively—in a way that coheres more or less with the values she deems immediately relevant in the context of a specific choice — in the face of oppression. However, the agent who faces oppression cannot be autonomous. The absence of autonomy will impact her expression of agency; but, it will not make it impossible. An agent can navigate within her relationships to maximize the pursuit of her own interests despite structures that impose limits on the values, selfconcepts, and choices for action reasonably available to her. A person's agency could be strengthened by improving her ability to negotiate within her relationships with others in the face of her oppression.

This further reinforces the importance of the interconnected abilities of relationality, emotionality, and rationality to agency. Since the world in which choices are constantly being made is itself imperfect and relationally structured, there will be many instances where people will need to negotiate, rather than resist, their relationships with other people to most effectively maintain their agency. This woman, without a husband, may lose social standing and much needed resources. She may endure fewer faces of oppression by making choices that maintain instead of end her personal relationships even if those relationships impose restrictions on her and the actions she can reasonably choose. She can sort through these options within oppressive social 
conditions: those conditions inform her relationality, emotionality, and rationality in ways that help her determine how to maintain those relationships she needs most. Since people can still effectively express their agency within oppressive social conditions, there is a need for a separate account to identify the limits that are imposed on agents by social conditions. An account of autonomy would then address the broad network of relationships and whether they impose restrictions on the agents existing within that particular network.

In the next section, I will outline the details of a relational account of autonomy. A relational account of autonomy indicates that it is the underlying social structures governing agents' actions, choices, and values that must be dismantled for complete autonomy to be possible for all agents. At present, due to the prevalence of oppression, I must conclude that many agents are not fully autonomous: they cannot fully control the way their lives go. I also must conclude that the solution to the absence of conditions that are conducive to autonomy is itself very difficult to achieve. However, this does not make such things impossible. It is just important to recognize that oppressed agents should not be held personally responsible for their experiences of oppression even if they make choices that work within oppressive structures instead of against them. I will defend the claim that individualized resistance by oppressed agents cannot effectively change conditions that are not conducive to autonomy in Chapter 4. Instead, it is the collective responsibility of many agents working together to take the steps necessary for making structural changes required for removing oppression such that social conditions can be more conducive to autonomy for all agents. 


\section{$\underline{\text { A Relational Account of Autonomy }}$}

I draw on the accounts of relational autonomy developed by Susan Sherwin and Catriona Mackenzie to supplement Miller's expanded account of agency. Sherwin advances an account of autonomy that is sensitive to the troubling effect of oppression on agents. Sherwin's account of relational autonomy is as follows:

In using the term 'relational autonomy,' I mean to invoke the socially and politically situated positions in which persons live and from which they may exercise (or seek to exercise) control over aspects of their lives that are important to them. I use this concept to make visible the ways in which specific details of agents' embodied identity, and the social practices that shape their experiences, may affect the degree of autonomy available to them. ${ }^{180}$

Autonomy then refers to the ability to control relevant aspects of one's life. Sherwin points out that this occurs within a social and political landscape that can affect how much control an individual truly has over the course of her life. Sherwin's account recognizes the embodied reality of agents and the effect such realities have on the possibility for autonomy. A relational account of autonomy is adequately sensitive to the impact relationships can have on the control an individual is able to exert over her own life. Relationships shape our social worlds as well as our understandings of ourselves and of others. This in turn is implicated in our ability to control our own lives as everything is mitigated by the presence of relationships in our lives, many of which are unchosen. As relationships structure our realities they will necessarily affect us and since they affect us they will affect the control we have over our own lives.

A relational account of autonomy is specifically sensitive to the relational nature of human lives and social worlds. Autonomy, when considered relationally, is understood to be conditioned relationally. The degree to which an individual can control aspects of

180 Sherwin, "Relational Autonomy and Global Threats", 13. 
her life depends a lot on the socially and politically situated position in which that person is embedded. The broader scheme of relationships, insofar as they shape the individual, can facilitate or constrain the expansion of what is within the realm of control for the specific agent. As Mackenzie highlights:

Relational theorists stress that neither our choices nor these aspects of the self are sui generis; rather, they are shaped and constrained by the social relationships and environments in which we are embedded. We form, sustain, and revise our self-identities in relational connections to specific others, and we negotiate our sense of individual selfhood in a specific geographical, historical, and political context and in relation to intersecting social determinants, such as gender, race, ethnicity, ability, and class. ${ }^{181}$

Conceiving of autonomy relationally draws attention to the effects of relationships on the control individuals can have over their own lives in a way that Sen's and Miller's accounts alone were unable to. The relational lens helps one to recognize the limited control agents have over the structures that shape their lives. We cannot have complete control over every aspect of our lives or everything that can come to influence our lives. It is for this reason that Sen's preoccupation with expanding freedom alone cannot accommodate all the barriers to effective expressions of agency. Also, Miller's restricted focus on the individual level and their particular moral obligations does not leave room for the role of the broad network of relationships in agents' lives.

A relational approach to autonomy handles many of the problems more traditional accounts of autonomy have faced by being better able to account for the varied influences on an agent's ability to act autonomously. More traditional accounts of autonomy assume

\footnotetext{
${ }^{181}$ Catriona Mackenzie, "The Importance of Relational Autonomy and Capabilities for an Ethics of Vulnerability" in Vulnerability: New Essays in Ethics and Feminist Philosophy, ed. Catriona Mackenzie et al. (New York: Oxford University Press, 2014), 43.
} 
the self is "self-defining, self-interested, and self-protecting." "182 This sort of account "idealizes decisions that are free from outside influence without acknowledging that all persons are, to a significant degree, socially constructed, that their identities, values, concepts, and perceptions are, in large measure, products of their social environment." In virtue of the fact that people are relationally embedded and significantly affected by the broad scheme of relationships within which they are embedded, an account of autonomy must be expanded to incorporate this fact. Otherwise, a more impoverished account of autonomy will be unable to identify all cases where autonomy is missing as well as fail to offer insights into effective solutions for restoring people's autonomy. In this way, autonomy must be conceived of relationally in order for it to be a workable concept.

Social conditions can be more or less conducive to autonomy depending on the kinds of restrictions they impose on particular individuals within that society. A society with very strict definitions affixed to identities, traits, and reasonable values will be far less conducive to autonomy than a society that has few such restrictions. When oppression is less prevalent within a society, and that society is very permissive concerning the varied ways people may choose to navigate the world on their own terms, that society is more conducive to autonomy. However, this is not a feature of our world. Oppression is actually quite prevalent in our own society. Since societies all exhibit social categories that can be more or less restrictive, full autonomy for all members of society does not at this moment in time exist.

182 Susan Sherwin, “A Relational Approach to Autonomy in Health Care," in The Politics of Women's Health: Exploring Agency and Autonomy, coord. Susan Sherwin (Philadelphia: Temple University Press, 1998), 34.

183 Sherwin, "Autonomy in Healthcare," 35. 
Conditions that are not conducive to autonomy will impact the effectiveness of individual expressions of agency. This is because problems with the broader network of relationships will inevitably come to affect the individuals who exist in those relationships. Ideally, a society would leave it open to individuals to decide for themselves what they should be. In other words, a society that leaves such definitions open and plural will possess conditions that are more conducive to autonomy and will thereby strengthen its members' ability to effectively express their agency. People who are able to pick and choose from an assortment of possible meanings and can themselves choose which social groups they participate in are better placed to be autonomous. Structures in which faces of oppression manifest must be dismantled. Until that happens, complete autonomy for all agents is not present. My discussion of oppression makes it clear that social conditions characterized by oppression will have an immense impact on the agents within those conditions. Yet, I have argued that, even in conditions of oppression, it is possible for oppressed persons to effectively express their agency. However, oppressed persons cannot be completely autonomous.

\section{$\underline{\text { Conclusion }}$}

Although oppressed agents will be constrained by the broad framework of relationships through which expressions of agency take place, a particular oppressed agent may not be completely and uniformly limited throughout all of her relationships. Through the use of their agential skills, agents can mitigate the negative effects of oppressive social conditions. I argue that agency can remain even when agents lack complete control over all the circumstances that structure their lives. Within oppressive social structures, there will remain an option that coheres best with an agent's values and goals even if in 
different conditions she would make a different choice. Since agency can be present in the face of oppression, something else must be absent.

It is for this reason that an account of agency must be supplemented with an account of autonomy.

Autonomy cannot be expanded through a restricted focus on the agents making choices that are not autonomous. It is the broad social conditions that need to change in order to increase autonomy as little can be done by particular oppressed agents on their own to disrupt those norms. In the following chapter, I will discuss ways in which agents can effectively change oppressive social conditions that are not completely conducive to full autonomy for all agents. I will argue against an account the requires individualized resistance to a broad network of relationships and instead argue that it will require the collective efforts of many agents working together, in solidarity, for broad social conditions to change such that they no longer oppress agents. 


\section{Chapter 4}

\section{Changing Conditions: Resistance in the Face of Oppression}

\section{$\underline{\text { Introduction }}$}

While the last chapter explored in great detail the effects and limits agents will face when oppressed, there remain possibilities for oppressed agents to challenge their oppression within particular relationships. In this chapter, I will discuss the ways in which agents can challenge broad social conditions. First, I will address Diana T. Meyers's account of autonomy. Her account requires agents to resist relational pressures when they conflict with their authentic selves in order to maintain their autonomy. I will argue that resistance, when considering the thoroughly relational nature of agents and the impact of the broad network of relationships on agents, is incredibly difficult for and potentially damaging to oppressed agents. I will also argue that Meyers's presumption that there exists a singular, unified 'authentic' self for agents to find is implausible considering the thoroughly relational nature of human selves. Most agents, and oppressed agents in particular, will be best served by finding ways to navigate and negotiate instead of resisting the broad network of relationships in which they are embedded.

In place of resistance, I suggest that non-autonomous agents can find ways of challenging oppressive structures in and through their relationships with other people. I will offer Iris Marion Young's 'social connection model' of responsibility as she argues that responsibility for oppression can only be discharged collectively: by agents uniting with others to work together to change oppressive social conditions. I will then introduce the concept of 'solidarity' as a unifying method through which agents can work together to dismantle oppressive social conditions. In particular, I will draw on accounts from 
Young, Sally Scholz, Alexis Shotwell, and Chris Dixon as they all offer suggestions for helping groups of agents build solidarity and find productive ways to dismantle oppressive social conditions through solidarity. For solidarity to most effectively combat oppressive structures, agents must utilize relational, emotional, and rational capacities in ways that are sensitive to the effects of oppression. While my discussion of these big topics will be limited to this final chapter, I intend to demonstrate that it is possible for agents to work together well and effectively to make the major changes necessary to dismantle oppressive conditions that are not completely conducive to full autonomy for all agents. To fully address this argument is beyond the scope of this thesis. Additional work in this area would be valuable for identifying ways in which oppressed agents can collectively make the changes necessary to end their oppression. For now, I only introduce the concept of solidarity as one possibility for the collective action of agents.

\section{Meyers's Account of Autonomy}

According to Meyers, "personally autonomous agents control their own lives." 184 Autonomous agents are not forced to do things and are able to mitigate the effects of their relational contexts. For Meyers, someone controls her own life if she is able to choose how her life goes and does not "allow outside forces to displace [her] own desires." ${ }^{185}$ To do this effectively requires self-discovery, self-definition, and self-direction. ${ }^{186}$ This is because "to achieve personal autonomy, one must know what one is like, one must be able to establish one's own standards and to modify one's qualities to meet them, and one

\footnotetext{
184 Meyers, Self, Society, and Personal Choice, 19.

185 Ibid.

${ }^{186}$ Meyers, Self, Society, and Personal Choice, 20 and 43.
} 
must express one's personality in action." ${ }^{187}$ A person requires extensive knowledge of how she would like her life to go to control her life on her own terms. Meyers argues that, "to be in control of one's life is...to live in harmony with one's true-one's authentic_-self." ${ }^{188}$ Meyers argues that self-discovery, self-definition, and self-direction makes autonomy possible because they allow one to determine what her authentic self is and what living in harmony with that authentic self would look like. These three competencies are closely connected as each relies on the others in practice. ${ }^{189}$

\section{The Three Competencies: Self-discovery, Self-definition, and Self-direction}

Meyers argues that the self must possess knowledge of her own volitions and what she would like her self-determined projects to consist in to affect change that is truly in accordance with her own volitions. Self-knowledge is required to demonstrate autonomy and requires the ability to read the self and determine which aspects of the self are authentically one's own. ${ }^{190}$ Meyers claims knowledge of the self comes through introspection and reflection on what the self is truly feeling and what one's genuine response to the world around her should be. ${ }^{191}$ One must be honest with oneself in terms of those self-concepts that do not truly match her deepest values even in the face of social pressures to maintain them.

Self-definition is related to and builds on self-discovery. According to Meyers, "autonomous people can adjust their own characteristics along with their behavior to match their respective conceptions of what kind of people they should be and what kind

\footnotetext{
${ }^{187}$ Meyers, Self, Society, and Personal Choice, 20.

188 Meyers, Self, Society, and Personal Choice, 19.

${ }^{189}$ Meyers, Self, Society, and Personal Choice, 80.

190 Meyers, Self, Society, and Personal Choice, 79.

191 Ibid.
} 
of life is worthwhile."192 On this account, to exhibit autonomy, one must be able to sift through her self-concepts, maintain those that fit, and work to change the ones that do not. Meyers argues that self-definition must be completely in the hands of the self in question as "people who know what they are like but despise themselves or systematically suppress their own desires, attachments, values, and so forth, lack integrated personalities and are not autonomous."193

The final competency described by Meyers is self-direction. This refers to the ability to determine where the self wants to go- the actions it may wish to pursue in the world — and then actually taking it there. Meyers claims "autonomous people must be able to envisage life plans, and they must be able to fulfill the standards implicit in these plans." ${ }^{194}$ One must be capable of determining, based on her deepest values, what she would want her life to look like. The competencies together allow a person to discover and continuously shape herself authentically while ensuring she can govern the course of her life in terms of this authentic self. This, according to Meyers, allows one to act autonomously as to act autonomously is just to act in ways that match one's actual and authentically defined self. $^{195}$

\section{$\underline{\text { Resistance and Resolve }}$}

Meyers includes the concepts of resistance and resolve in her account of autonomy as these concepts add force to self-direction by making it possible for people to actually direct themselves authentically. She claims that "to be self-directing, a person must be

\footnotetext{
192 Meyers, Self, Society, and Personal Choice, 80.

193 Ibid.

194 Ibid

195 Meyers, Self, Society, and Personal Choice, 17.
} 
able to resist unwarranted pressure from other individuals ... must be able to resist automatic conformity to societal norms ... and must be able to resist impulses stemming from disapproved traits or discredited beliefs. ${ }^{196}$ Self-direction requires resistance in the face of pressures that do not match the authentic self. According to Meyers, to maintain control over one's life — and exhibit autonomy_one must resist the influence of others when determining what choices one should be making. ${ }^{197}$ People must be able to resist the pressures exerted by friends and family if these are at odds with their authentic self. One must also resist the restrictions imposed by broad social structures that delineate what behavior is normal and acceptable in those cases where they are at odds with one's authentic self. Finally, there will be times when one is in the process of defining herself in a new way and to be autonomous she must resist the influence of self-concepts that no longer coincide with what she would like her authentic self to be. Resistance must be coupled with resolve. Meyers's describes resolve as “a person's determination to act on his or her own judgments." ${ }^{\prime 198}$ It is not enough to resist forces that limit one's autonomy: one must also possess the resolve to realize this resistance in action. Meyers's explains "autonomous people need to be capable of standing by their own judgements despite the opposition or faint encouragement of others." ${ }^{\prime 199}$ They must have the resolve to resist the relational influences that conflict with their authentic selves.

\section{Problems with Meyers's Account of Autonomy}

There are two main problems with Meyers's account. First, Meyers is working from an individualistic conception of selves. She believes particular selves possess coherent life

\footnotetext{
196 Meyers, Self, Society, and Personal Choice, 83.

197 Ibid.

198 Ibid.

199 Meyers, Self, Society, and Personal Choice, 84.
} 
plans toward which they can focus all their energies. She also seems to assume that there is a singular, unified, coherent authentic self that agents can discover by turning inward and reflecting. I have already argued that there are many problems with an account that is not sensitive to the thoroughly relational nature of agents. I also argued that selves may possess self-concepts and values that are multiple, contradictory, and conflicting and that this means a singular authentic self does not exist. Agents can use these aspects of themselves to better navigate the broad network of relationships within which they are embedded by prioritizing needs and values in some relationships over others depending on what the broad social conditions permit in terms of those agents' choices. Conditions of oppression mean that most often there will not be a singular life plan that an agent can devote all her energy toward achieving. Since these are precisely those conditions that necessarily limit autonomy, Meyers's suggestions concerning self-knowledge, selfdefinition, and self-direction mean that most agents will struggle and fail to be more autonomous. Our selves are multiple and diverse. It will not always be obvious to an agent which particularly relevant self-concepts or values should be prioritized within specific relationships. Reflecting, or turning inward, will not provide the agent with all the insight needed concerning how she should proceed. Agents will need to use their skills of relationality, emotionality, and rationality to determine how they can express their agency most effectively within a particular relational context.

A second problem is Meyers's argument that agents must resist relational pressures individually in order to maintain autonomy. I have already argued that oppressive relationships are precisely those that cannot be resisted on one's own. Also, since relationships are constantly present and all agents are embedded in a broad network 
of varied relationships, people will have a variety of good reasons to want to embrace, maintain, and navigate the influence of others in their lives. Agents choose to consistently work within their relationships to effectively express their agency. This means that an account of autonomy that requires agents to resist instead of work with others will be inconsistent with the fact of relationality.

Resistance can be incredibly difficult within personal relationships and in terms of the broad network of relationships that structure social conditions. Oppression flows from the broad network of relations in ways that affect particular relationships and the particular agents within those relationships. As I discussed in Chapters 2 and 3, personal relationships are shaped by broader patterns of relationship and both levels will affect particular agents. The relationships that make up this broad network are "shaped by social practices and political contexts" which are often deeply entrenched and difficult to alter without the concerted effort of many participants within a society. ${ }^{200}$ There exist certain rules and norms in social environments that will implicate certain behaviours and traits as acceptable and others as odd or strange. Individuals will often feel social pressure to conform to the norms of their society and they will suffer consequences for failing to maintain or participate in structures that assume those norms. ${ }^{201}$ Depending on how entrenched or oppressive certain societal norms are, it may be impossible for particular oppressed agents to truly question or resist them alone. There may be no real alternatives because an agent who is oppressed does not have a choice in whether or not she is subjected to those norms. Those who are oppressed are not autonomous in the sense that Meyers endorses. Yet they are precisely the agents that Meyers would call on to resist.

\footnotetext{
${ }^{200}$ Koggel, "Relational Approach to Equality," 71.

201 Sherwin, "Relational Autonomy and Global Threats", 19.
} 
Just as I argued against Sen for suggesting women should do their best to resist their oppression through participating in the market, Meyers similarly calls for agents to work against, instead of within, systems of oppression. However, agents who resist their oppression on their own will likely face greater harm and further oppression. There may be choices agents would prefer to make and values they would prefer to prioritize overall. Given the particularities of the context of any given choice, agents may decide they need to choose to prioritize specific concerns and values that conflict with what they would choose if the broad social conditions were different. In any case, individual resistance to all relational influences that bear on a particular agent cannot make a non-autonomous agent autonomous. Those conditions must change completely, not merely be resisted by particular oppressed agents.

In the following section, I will offer possible strategies for agents to challenge oppressive social conditions. It will require the collective efforts of many agents working in solidarity with one another. This is a feasible alternative to the sort of resistance Meyers suggests. Since oppressed agents are precisely those who cannot resist the broad network of relationships by themselves, they must find other ways to disrupt existing social conditions. I will argue that it is through collective action that resistance is possible and thereby change to oppressive social conditions is attainable. It takes agents who work through their relationships with others instead of resisting them to be capable of challenging oppressive social conditions.

\section{What Can Be Done?: Solidarity and Collective Action}

Oppressed agents will be able to negotiate within their relationships with others to find ways to effectively express their agency despite restraints on their full autonomy. I have 
already discussed in Chapters 2 and 3 that due to the multiple, contradictory, and relational nature of selves, agents can find spaces within relationships with other people where they can act in ways that conform to the values they deem relevant in their own lives. In other words, there may be spaces where the restrictions imposed by conditions that are not conducive to full autonomy are not as strongly felt. This will likely be in relationships with others who are sensitive to an agent's particular experience of oppression. Sensitivity to the differing experiences of oppression other agents have can perhaps come out of an agent's own experience of oppression. It could also come out of an agent's willingness to recognize their own privilege should they not have shared in those experiences of oppression themselves. On a personal level, this provides certain agents with opportunities to express their agency most effectively despite broad social conditions that impose limits on their agency more generally.

Just as agential skills provide insight to agents looking to effectively express their agency, they allow agents to understand the experiences of others even in cases where their particular experiences are fundamentally different. For instance, while a particular 'man' may not share in the same experiences of oppression that a particular 'woman' has had, he can learn about her experiences through the use of relational, emotional, and rational skills. He can listen to and validate her experiences even in a society that constantly calls those experiences into question. Agents can recognize the presence of different faces of oppression whether or not these directly limit and constrain their own actions through their relationships with others who are more directly affected by that oppression. Within these relationships, agents will need to work to understand the differing experiences of oppression of other agents. This means it will require effort- 
and the use of relational, emotional, and rational skills - by agents in order for them to be sensitive to the effects oppression has on others with whom they are in relationship.

While resistance cannot feasibly be undertaken by agents acting alone, there are initiatives that can be undertaken by agents acting together that will effectively initiate broader social changes necessary for forging social conditions that are more conducive to autonomy. Sherwin suggests societies must "develop and pursue policies and programs that will make available (and attractive) options that will help agents reduce, rather than reinforce, patterns of oppression and enable them to identify options that are compatible with their deepest values and needs." 202 Institutions must themselves change the norms embedded in them such that they do not maintain and promote oppressive norms.

However, this is only one of the changes that would need to happen. Just as many agents participate in the constitution of a broad network of relationships, it will require many agents working together to effectively dismantle existing, oppressive social conditions.

\section{$\underline{\text { Social Connection Model }}$}

Young explains that "the 'social connection model' of responsibility says that all agents who contribute by their actions to the structural processes that produce injustice have responsibilities to work to remedy these injustices."203 Since oppression comes out of the social structures that are themselves comprised of numerous relationships in which agents participate, all agents within oppressive social conditions bear some responsibility for making the changes needed to end those oppressive structures. As Young argues, "the shared responsibility for undermining injustice can be discharged only through collective

202 Sherwin, "Relational Autonomy and Global Threats," 19.

${ }^{203}$ Iris Marion Young "Responsibility and Global Justice: A Social Connection Model” 2006, 102-103. 
action. Agents who participate in processes that produce injustice often need to reorganize their activities and relationships to coordinate their action or coordinate it differently."204 Agents may need to make serious changes within their lives and relationships with others to alter the patterns of oppression and to do so together. Agents will need to coordinate their efforts to make serious changes because these changes will require the collective efforts of diverse agents.

Young defends her claim that the responsibility generated by the social connection model must be discharged collectively because of,

The essentially shared nature of the responsibility. Thousands or even millions of agents contribute by their actions in particular institutional contexts to the processes that produce unjust outcomes. Our forward-looking responsibility consists in changing the institutions and processes so that their outcomes will be less unjust. No one of us can do this on our own. ... The structural processes can be altered only if many actors in diverse social positions work together to intervene in these processes to produce different outcomes. ${ }^{205}$

All agents participating in this broad network of relationships are each partially responsible for the creation of the overarching oppressive social conditions. I have already argued that particular acts of resistance within relationships are not going to allow for the major structural changes required for dismantling the underlying norms and oppressive social conditions. The solution will require the efforts of many agents working together since it is many agents existing in relationships with one another who participate in chains and connections that cause these problems in the first place. While it is true that individually agents may be incapable of dismantling these overarching conditions, when agents work together it can be possible to make the major structural changes needed to at least alleviate if not end oppression

\footnotetext{
204 Young, Responsibility for Justice, 146-147.

205 Young, "Responsibility and Global Justice," 123.
} 
Young has argued that all agents within a broad network of relationships are responsible for making changes collectively to end oppression. I will now introduce the concept of solidarity as one possible option for oppressed agents to work together to dismantle oppressive social conditions. I will also offer some concerns solidarity movements must be sensitive to in order to avoid perpetuating, instead of ending, oppressive structures. I offer an account of solidarity to demonstrate that collective responsibility can be discharged through the unity of agents working toward the shared goal of dismantling oppressive social conditions.

\section{$\underline{\text { Solidarity }}$}

Resistance is made possible through solidarity. Sally Scholz remarks that "political solidarity is a unity of individuals each responding to a particular situation of injustice, oppression, social vulnerability, or tyranny." ${ }^{, 206}$ Scholz also claims that "solidarity is a unity that mediates between the individual and the solidarity community as well as the larger community. The range of resistance, protest, or oppositional actions varies tremendously from formal challenges to the law to conscious awareness of the political impact of personal decisions. ${ }^{207}$ Agents manifest resistance through solidarity with one another and together they can impact broad social conditions in ways that actions undertaken alone cannot. Acts of resistance can vary through solidarity. This means that the varied steps that need to be taken to dismantle oppressive conditions are possible: from more formal changes to changes within social understandings of groups of united

\footnotetext{
206 Sally J. Scholz, Political Solidarity, (University Park: The Pennsylvania State University Press, 2008), 51.

207 Scholz, Political Solidarity, 54.
} 
agents. Solidarity makes a variety of different sorts of challenges to existing oppressive norms and structures possible.

Solidarity is also inherently relational as it requires that agents work together, within a broad network of relationships. Returning to Young, she claims that "solidarity is a relationship among separate and dissimilar actors who decide to stand together, for one another. ... Solidarity must always be forged and reforged." ${ }^{208}$ Like Scholz, Young cashes out solidarity in relationally sensitive terms. Young adds that dissimilar actors who unify through solidarity "recognize and take up shared responsibility in relation to the social institutions and practices they enact and support, to make them just." ${ }^{209}$ Solidarity comes out of agents collectively recognizing their responsibility in the creation of oppressive social conditions through their participation in a broad network of relationships. Agents can work together to find ways to act in solidarity to address those oppressive conditions.

Working in solidarity with others requires recognizing that existing conditions are oppressive and believing that things could be different. As Young explains,

People who understand themselves in solidarity with close and distant others aim to work together to improve the state of well-being of themselves and/or others. They take an active approach to history, which means they do not accept the past as determining the present and the future. Rather than take existing social structures and relations as what they are, as given, they take them as possibilities - perhaps things can be improved. ... Let us try together to alter the social processes that we understand produce injustices, and perhaps we will have some success. ${ }^{210}$

Solidarity does not guarantee that existing social structures will be upended. It also does not guarantee a swift end to oppression. However, solidarity makes major social changes

\footnotetext{
${ }^{208}$ Iris Marion Young, Responsibility for Justice, (New York: Oxford University Press, 2011), 120.

${ }^{209}$ Young, Responsibility for Justice, 121.

${ }^{210}$ Young, Responsibility for Justice, 120.
} 
possible. It is possible for agents to work together to change the entrenched norms, ideas, structures, institutions, and understandings: to reweave the broad network of relationships in a way that will end oppression in place of perpetuating it. In terms of practices that aim to end oppression, Chris Dixon notes that "on the one hand, they are our attempts to struggle in the world that is - a world structured by social relations of oppression and exploitation. On the other hand, they are our attempts to manifest the world that we want $-\mathrm{a}$ world built on egalitarianism, solidarity, and self-determination. ${ }^{, 211}$ It is about recognizing that the conditions can change: they can be made better in ways that are conducive to full autonomy for all agents. However, it will require the unified efforts of many agents for real change to take place.

Alexis Shotwell suggests that solidarity and affect can coincide. She explains that "working in solidarity often arises from affective stakes — caring for someone, outrage about an injustice, or aspiration for a changed world. The feeling work of solidarity is productive and transformative, making new expressive resources, which then engender new sites for solidarity struggles. ${ }^{.212}$ Solidarity is both relationally and emotionally grounded. Shotwell claims "as always relational, affect also articulates the potential for a kind of collective (rather than individualist), structurally/socially embedded (rather than voluntarist), holistic, multiaxial praxis. This sort of praxis is the ground for responsible solidarity. ${ }^{, 213}$ In this way, solidarity accommodates and can be developed through the emotionality and relationality of agents. Solidarity is then adequately sensitive to the realities of the thoroughly relational nature of agents and does not require the dismissal of

${ }^{211}$ Chris Dixon, Another Politics: Talking across Today's Transformative Movements (Oakland: University of California Press, 2014), 99.

${ }^{212}$ Alexis Shotwell, Knowing Otherwise: Race, Gender, and Implicit Understanding (University Park: The Pennsylvania State University Press, 2011), 100.

213 Shotwell, Knowing Otherwise, 122. 
the importantly interconnected skills of relationality, emotionality, and rationality. Shotwell notes that "one form of relational re-identification might be created through the process of acting in solidarity with others. This is a space that might come out of, and produce, new possibilities for action." 214 Solidarity may open up varied avenues for effectively expressing agency that agents did not have access to before. These avenues are not restricted to one sort of expression of agency but permit expressions that are emotional and relational too.

\section{Building Solidarity}

Dixon offers insights concerning important features solidarity movements should possess. ${ }^{215}$ These features would strengthen solidarity within anti-oppressive movements and between agents who choose to engage collectively in actions to disrupt oppressive structures. The first feature Dixon mentions "is an understanding of power relations as fundamentally intertwined.... We need to understand the histories that have shaped the systems that we fight, how these systems reinforce one another, and where we can best work to disrupt and transform them. ${ }^{, 216}$ Oppression comes out of historical experiences and understandings concerning which sorts of agents deserve what treatment. Many oppressed agents do not possess a singular and uniform experience of oppression. Each face of oppression will often be tied up in the others. For instance, challenging powerlessness may require an appreciation of the ways in which powerless agents are also exploited or threatened with violence within their lives. Agents must appreciate the

214 Shotwell, Knowing Otherwise, 98-99.

215 Dixon, Another Politics, 73-75.

216 Dixon, Another Politics, 73-74. 
intertwined and complex nature of oppression in order to organize most effectively to disrupt those norms.

A second feature Dixon identifies that unified agents must recognize are "the ways in which people replicate power relations in movements and in day-to-day lives. This comes from an understanding that, even as we fight social hierarchies, they have shaped us and we participate in reproducing them." ${ }^{217}$ It is important for agents looking to build solidarity to recognize the ways in which they may inadvertently maintain oppressive social conditions within their relationships with others. Insofar as all agents exist within a broad network of relationships characterized by oppression, all of those agents are then affected by those norms. It is possible that agents do not notice how the actions they engage in may maintain oppressive conditions. Dixon suggests that groups of agents who are working to disrupt oppressive structures can address "this challenge through consciousness-raising about oppressive dynamics and creating intentional organizational structures to shift power relations." ${ }^{.218}$

Consciousness-raising can be made possible by unifying agents with unique experiences such that they can inform one another of the numerous ways oppression can manifest. As Young points out, "victims of injustice ... often have unique insights into its social sources and the probable effects of proposals for change. ${ }^{.219}$ Oppressed agents are uniquely situated to best understand the ways oppressive social conditions affect agents. Oppressed persons may have a better understanding of which endeavours would best transform existing conditions. In joining with others, more privileged agents can learn

\footnotetext{
${ }^{217}$ Dixon, Another Politics, 74.

218 Dixon, Another Politics, 74.

${ }^{219}$ Young, "Responsibility and Global Justice," 128
} 
about the ways in which they participate in and maintain oppressive structures. It is important to draw on the knowledge and experiences of oppressed persons for solidarity that is truly sensitive to the effects of oppression. This will require relational, emotional, and rational skills for agents to understand the unique perspectives and experiences of others who are differently affected by oppression.

Privileged agents can also help make movements more effective as they are most likely better situated to make greater changes in their own actions to challenge broad social conditions. As Young explains "victims of injustice ... are unlikely to succeed without the help and support of other less-vulnerable people." ${ }^{220}$ It is for this reason that Dixon claims solidarity needs to occur "across power differences: those who experience privilege in a given context offering support, on a basis of equality and respect, to those who experience oppression in that context." ${ }^{221}$ Agents with greater advantages in the face of oppressive social conditions must work to understand the lives of less advantaged agents to then best engage in changing those conditions.

Dixon argues that solidarity between diverse agents can be enhanced in the face of oppression "by making the struggles of those who are exploited and oppressedworking-class people, people of color, women, gender-nonconforming people, queers, disabled people, among others - central in our movements, organizations, and campaigns. The basic idea is that these struggles, particularly when they combine, can potentially rupture power relations and open new ways of relating and organizing."222 Solidarity can help agents find new ways of expressing their agency so as to challenge oppression.

\footnotetext{
220 Young, "Responsibility and Global Justice," 129.

221 Dixon, Another Politics, 74.

222 Dixon, Another Politics, 74.
} 
Solidarity provides spaces within which agents can be autonomous: a place to challenge and address oppression, recognize its impact, and open up paths to action in spite of that oppression that were not previously available to those agents. When living under social conditions that dismiss the perspectives of the oppressed, solidarity can provide a space that recognizes and validates those experiences. When agents work together, they possess greater power to change social conditions than they did on their own. Solidarity makes upending oppressive conditions possible in a way that focusing on self-discovery, self-definition, and self-direction cannot achieve. One agent alone cannot change a broad network of relationships. However, when many agents participating in that network refuse to accept oppression and instead work together to end it, it is possible to make serious changes. Since agents do not exist alone or express their agency free from the influence of others and relationships they are in, agents will need to work together, in solidarity, to change the conditions restricting their autonomy.

\section{Concluding Remarks: Effective Expressions of Agency and Relationality}

This project began with Sen's presumption that expanding freedom can allow people to express their agency more effectively. In particular, he highlighted the importance of enhanced independence from others, the advancement of rationality through education and information, and individual participation in the creation of social values. I have argued throughout that agents cannot achieve full independence from others due to the fact of relationality. I argued that rationality is not the only faculty that matters for the effective expression of agency. Also, in the face of oppression, people cannot change broad social values simply through participation in public discussion because those discussions will be structured in ways that specifically silence, ignore, and dismiss their 
views. Oppressed agents face great obstacles to their effective expression of agency that the expansion of freedom alone cannot combat. Oppressed persons are restricted from being agents in ways that Sen's account cannot address.

I moved on to Miller's expanded account of agency and enriched it further. I argued that her account is still too individualistic due to her preoccupation with the moral duty to care. I instead couched her expanded account of agency in the thoroughly relational nature of agents. I argued that particular moral agents responding to the duty to care will often be unable to address the harms to agency caused by oppression. There is no individuated response that can combat the effects of oppression on agents.

I then discussed in great detail the structural nature of the oppression agents can face. I argued that this demonstrates that oppression can only be ended through a dynamic, relationally sensitive approach that would address the many levels on which oppression operates. I also argued for the addition of a relational account of autonomy alongside an expanded account of agency in order to address the different levels on which agents can be limited in their effective expression of agency. Oppressed agents can continue to express their agency. Therefore, a second concept is required to encapsulate what it is those agents are missing: autonomy.

In this final chapter, I have argued that it is through solidarity, working in and through our relationships with others, that systems of oppression can be effectively dismantled. Due to the nature of oppression, agents must unite and work together to challenge the structurally embedded and generated norms that impose limits on the effective expression of agency. Agents will be unable to separate themselves from the broad network of relationships in which they are embedded. It is our relationships with 
others that allow for effective expressions of agency. Therefore, to expand people's ability to effectively express their agency requires sensitivity to the fact of relationality and a concerted effort to act in solidarity with others to challenge and change oppressive structures and conditions. 


\section{Bibliography}

Anderson, Joel. “Autonomy and Vulnerability Entwined." In Vulnerability: New Essays in Ethics and Feminist Philosophy, edited by Catriona Mackenzie, Wendy Rogers, and Susan Dodds, 134-61. New York: Oxford University Press, 2014.

Aristotle. Aristotle: The Complete Works. Edited by Jonathan Barnes. Princeton:

Princeton University Press, 1984.

Baier, Annette C. "The Need for More than Justice." Canadian Journal of Philosophy 13 (1987): 41-56.

Baylis, Francoise. "The Self in Situ: A Relational Account of Personal Identity." In Being Relational: Reflections on Relational Theory and Health Law, edited by Jocelyn Downie and Jennifer J. Llewellyn, 109-131. Vancouver: UBC Press, 2012. Beutelspacher, Austreberta Nazar, Emma Zapata Martelo, and Verónica Vázquez Garcia. "Does contraception benefit women?: Structure, agency, and well-being in rural mexico." Feminist economics 9.2/3 (2003): 213-238.

Campbell, Sue. "Being Dismissed: The Politics of Emotional Expression" Hypatia 9.3 (1994): 46-65.

—. "Memory, Reparation, and Relation: Starting in the Right Places." In Being Relational: Reflections on Relational Theory and Health Law, edited by Jocelyn Downie and Jennifer J. Llewellyn, 132-160. Vancouver: UBC Press, 2012. Campbell, Sue; Letitia Meynell, and Susan Sherwin. Embodiment and Agency. University Park: The Pennsylvania State University Press, 2009.

Code, Lorraine. What Can She Know? Feminist Theory and the Construction of Knowledge. Ithaca: Cornell University Press, 1991. 
Crocker, David A. Ethics of Global Development: Agency, Capability, and Deliberative Democracy. New York: Cambridge University Press, 2008.

Crocker, David A. and Ingrid Robeyns. "Capability and agency." In Amartya Sen, edited by Christopher W. Morris, 60-90. Cambridge: Cambridge University Press, 2009. Cudd, Ann E., 2014, “Agency and Intervention: How (Not) to Fight Global Poverty.” In Poverty, Agency, and Human Rights, edited by Diana T. Meyers, 197-222. New York: Oxford University Press, 2014.

Drydyk, Jay. "When is Development More Democratic?"Journal of Human Development 6.2 (2005): 247-267.

__. "Empowerment, agency, and power." Journal of Global Ethics, 9.3 (2013): 249262.

Dixon, Chris. Another Politics: Talking across Today's Transformative Movements.

Oakland: University of California Press, 2014.

Fukuda-Parr, Sakiko. "The human development paradigm: operationalizing Sen's ideas on development." Feminist Economics, 9.2/3 (2003): 301-317.

Gasper, Des, and Irene Staveren. "Development as freedom - and as what else." Feminist Economics 9.2/3 (2003): 137-161.

Gilligan, Carol. In a Different Voice: Psychological Theory and Women's Development. Cambridge: Harvard University Press, 1982.

Hill, Marianne T. "Development as Empowerment.” Feminist Economics 9 (2003): 117135.

Kabeer, Naila. "Resources, Agency, Achievements: Reflections on the Measurement of Women's Empowerment." Development and Change 30.3 (1999): 435-464. 
— "Conflicts Over Credit: Re-Evaluating the Empowerment Potential of Loans to Women in Rural Bangladesh.” World Development 29.1 (2001): 63-84.

—. "Gender, poverty, and inequality: a brief history of feminist contributions in the field of international development." Gender \& Development 23.2 (2015): 189-205. Khader, Serene J. Adaptive Preferences and Women's Empowerment. New York: Oxford University Press, 2011.

_ . "Must Theorising about Adaptive Preferences Deny Women's Agency?” Journal of Applied Philosophy 29.4 (2012): 302-317.

—_. "Beyond Autonomy Fetishism: Affiliation with Autonomy in Women's Empowerment." Journal of Human Development and Capabilities 17.1 (2016): 125139.

Koggel, Christine. "Globalization and Women's Paid Work: Expanding Freedom.” Feminist Economics. Special Issue: Amartya Sen's Work and Ideas 9.2/3 (2003): 163184.

__. "A Relational Approach to Equality: New Developments and Applications." In Being Relational: Reflections on Relational Theory and Health Law, edited by Jocelyn Downie and Jennifer J. Llewellyn, 63-88. Vancouver: UBC Press, 2012.

Kosko, Stacy J. "Agency vulnerability, participation, and the self-determination of indigenous peoples." Journal of Global Ethics 9.3 (2013): 293-310.

Mackenzie, Catriona. "The Importance of Relational Autonomy and Capabilities for an Ethics of Vulnerability." In Vulnerability: New Essays in Ethics and Feminist Philosophy, edited by Catriona Mackenzie, Wendy Rogers, and Susan Dodds, 33-59. New York: Oxford University Press, 2014. 
Mackenzie, Catriona and Natalie Stoljar, eds. Relational Autonomy: Feminist

Perspectives on Autonomy, Agency, and the Social Self. New York: Oxford University

Press, 2000.

Meyers, Diana T. Self, Society, and Personal Choice. New York: Columbia University Press, 1989.

— ed. Feminists Rethink the Self. Boulder: Westview Press, 1997.

— ed. Poverty, Agency, and Human Rights. New York: Oxford University Press, 2014.

Miller, Sarah Clark. “Cosmopolitan Care.” Ethics and Social Welfare 4.2 (2010): 145157.

- The Ethics of Need: Agency, Dignity, and Obligation. New York: Routledge, 2012.

Mohanty, Chandra Talpade. "Under Western Eyes: Feminist Scholarship and Colonial Discourses." Feminist Review 30 (1988): 61-88.

Nedelsky, Jennifer. Law's Relations: A Relational Theory of Self, Autonomy, and Law. New York: Oxford University Press, 2011.

Nussbaum, Martha C. The Therapy of Desire: Theory and Practice in Hellenistic Ethics. Princeton: Princeton University Press, 1994.

-Women and Human Development: The Capabilities Approach. Cambridge:

Cambridge University Press, 2000.

. "Capabilities as Fundamental Entitlements." Feminist Economics 9 (2003): 33-

59. 
—. Frontiers of Justice: Disability, Nationality, and Species Membership.

Cambridge: Harvard University Press, 2006.

—. Creating Capabilities: The Human Development Approach. Cambridge: Harvard University Press, 2011.

Olsaretti, Serena. "Endorsement and Freedom in Amartya Sen's Capability Approach." Economics and Philosophy 21.1 (2005): 89-108.

Peter, Fabienne. "Gender and the foundations of social choice: The role of situated agency." Feminist economics 9.2/3 (2003): 13-32.

Robeyns, Ingrid. "The Capability Approach: a theoretical survey." Journal of Human Development 6.1 (2005): 93-114.

_. "The Capability Approach in Practice." Journal of Political Philosophy 14.3 (2006): 351-76.

Scholz, Sally J. Political Solidarity. University Park: The Pennsylvania State University Press, 2008.

Sen, Amartya. "Well-Being, Agency and Freedom: The Dewey Lectures 1984." The Journal of Philosophy 82.4 (1985): 169-221.

—. Inequality Reexamined. New York: Oxford University Press, 1995.

—. Development as Freedom. Oxford: Oxford University Press, 1999.

—. The Idea of Justice. Cambridge: Harvard University Press, 2009.

Sherwin, Susan. "A Relational Approach to Autonomy in Health Care." In The Politics of Women's Health: Exploring Agency and Autonomy, coordinated by Susan Sherwin, 19-47. Philadelphia: Temple University Press, 1998. 
_. "Relational Autonomy and Global Threats" In Being Relational: Reflections on Relational Theory and Health Law, edited by Jocelyn Downie and Jennifer J.

Llewellyn, 13-34. Vancouver: UBC Press, 2012.

Shotwell, Alexis. Knowing Otherwise: Race, Gender, and Implicit Understanding.

University Park: The Pennsylvania State University Press, 2011.

Tronto, Joan C. Moral Boundaries: A Political Argument for an Ethic of Care. London:

Routledge, 1993.

—. "Creating Caring Institutions: Politics, Plurality, and Purpose." Ethics and Social Welfare 4.2 (2010): 158-171.

__. "Partiality Based on Relational Responsibilities: Another Approach to Global Ethics." Ethics and Social Welfare 6.3 (2012): 303-316.

Walker, Margaret Urban. "Moral Understandings: Alternative 'Epistemology' for a Feminist Ethics." Hypatia 4.2 (1989): 15-28.

Young, Iris Marion. Justice and the Politics of Difference. Princeton: Princeton University Press, 1990.

—_. "Responsibility and Global Justice: A Social Connection Model." Social Philosophy and Policy 23.1 (2006): 102-130.

—. Responsibility for Justice. New York: Oxford University Press, 2011. 